\title{
Natural product sciences: an integrative approach to the innovations of plant natural products
}

\author{
Yuemao Shen $^{1} \&$ Xiaojiang $\mathrm{Hao}^{2 *}$ \\ ${ }^{1}$ Key Laboratory of Chemical Biology of Natural Products, School of Pharmaceutical Sciences, Shandong University, Jinan 250012, China; \\ ${ }^{2}$ State Key Laboratory of Phytochemistry and Plant Resources in West China, Kunming Institute of Botany, Chinese Academy of Sciences, \\ Kunming 650201, China
}

Received May 3, 2020; accepted August 11, 2020; published online September 14, 2020

\begin{abstract}
The study on plant natural products not only helps us understand that their structural diversity is the inevitable result of plant species diversity, but also helps us understand certain rules and unity of the inevitable connection between the two. The diversity and complexity of chemical structures of many natural products are beyond imagination before we elucidated their structures. The question that follows is what is the biological significance of these natural products. Intrigued by the relationship between plant resources, natural products and biological functions, the Hao laboratory has taken an integrative approach that employs tools and knowledge from multi-disciplines, including natural product chemistry, chemical ecology and chemical biology, to unveil the effects of plant natural products on plant resistance to diseases, and environmental acclimations. Collaborating with cell biologists, the research has resulted in discovery of new mechanisms of cellular signaling and lead compounds.
\end{abstract}

plant natural product, chemical structure, biological significance

Citation: Shen, Y., and Hao, X. (2020). Natural product sciences: an integrative approach to the innovations of plant natural products. Sci China Life Sci 63, 1634-1650. https://doi.org/10.1007/s11427-020-1799-y

\section{Introduction}

Natural products are collections of small-molecule metabolites synthesized by organisms via both the so-called primary and secondary metabolisms. Since the isolation of morphine from Opium poppy (Papaver somniferum) by Friedrich Wilhelm Sertürner in 1805 - the beginning of scientific natural product research (Goerig and Schulte am Esch, 1991), there have been over 300,000 natural products reported (https://www.routledge.com/go/the_dictionary_of_ natural_products). These natural products underlie many disciplines. For example, morphine, quinine, aspirin, penicillin (cephalosporins), rifamycins, vancomycin, taxol, and artemisinin are amongst the most representative natural products in modern pharmacy. Avermectins, validamycins,

\footnotetext{
*Corresponding author (email: haoxj@mail.kib.ac.cn)
}

pyrethrins and azadirachtins are the most widely used natural pesticides. Colchicine binds to the microtubule (D) end and decreases microtubule dynamicity, thus is an important tool in cell mitosis research, which has opened a new chapter in the field of karyomorphology. Cytochalasins bind to the plus end of microfilaments resulting in inhibition of both the association and dissociation of actin subunits, selectively and reversibly blocking cytokinesis without affecting karyokinesis, such that they are indispensable tools in cytology research including the mechanisms of cytoskeletal dynamics, microfilament-based trafficking of organelles and vesicles, phagocytosis, cell motility, and the production of lamellipodia and microspikes. Moreover, the study on rapamycin has revealed a series of signal transduction mechanisms in the process of immunosuppression, and the study of its target mTOR has a profound influence on cell biology.

Natural product research in China used to mainly focus on 
plants and traditional Chinese medicines. It is generally accepted that the beginning was the isolation and crystallization of tetrahydropalmatine from Yan $\mathrm{Hu}$ Suo (Chou, 1928). The contributions of the deified pioneer generation underlay our present natural product research, including peimine (Chi et al., 1936), peiminine (Chu and Chou, 1947), Aconitum alkaloids (Chu, 1955), securinine (Liang, 1963), organic analytical chemistry (Chen, 1953), and Fritillaria alkaloids (Chu et al., 1955). Currently, our research covers almost every fields of natural products. Herein, we attempt to provide an overview of some of the important advances from the Hao laboratory.

\section{The diversity of plant natural products in Southwest China}

The diversity of plants creates the diversity of plant natural products. Southwest China is known as the "Kingdom of Plants". A tremendous variety of plants and their folk usages are the cornerstones for the formation and development of Chinese medicine, which is also the foundation of the research on plant natural products developed in Kunming Institute of Botany, Chinese Academy of Sciences. The high diversity of plant natural products in Southwest China has been demonstrated by the systematic investigation on steroidal saponins (Zhou, 1964), triterpene saponins (Qiao et al., 2018), triterpenoids (Fang et al., 2011; Zhou et al., 1975), diterpenoids (Liu et al., 2017; Sun et al., 2006), and diterpene alkaloids (Hao, 2009). This section will present these spectaculars by highlighting some examples from the Hao laboratory.

Daphniacetal A is a monoterpene with an oxa-cage, and could be a derivative of isosantene (Figure 1) (Kong et al., 2009). Trigoflavidones A-E were novel 3,4-seco-diterpenoids isolated from the stems of Trigonostemon flavidus. Each of them has interesting novel structure features, but trigoflavidone $\mathrm{E}$ is the most striking one in that it contains a unique five-membered ring fused with a cyclopropane ring (Tang et al., 2012). Hedychins A and B are diterpenoids too (Figure 1). They are derived from the labdane-type diterpenoids of bearing an unprecedented 6,7-dinor-skeleton and a peroxide bridge (Zhao et al., 2018b). The peroxide bridge is rare in natural products. There are only a few examples including artemisinin (Artemisinin Structure Research Collaboration Group, 1977). Lathyranone A is a novel diterpenoid with a rearrangement skeleton, which could be derived from Euphorbia factor $\mathrm{L}_{11}$ via pinacol rearrangement (Gao et al., 2007). Rearrangement is one of nature's strategies to diversify the structures of natural products. For example, kansuinone is a rearranged euphane-type triterpenoid containing a spiro[5,6] ring system (Figure 1) (Guo et al., 2010).

Phenols are a large family of natural products including anthranols and flavonoids. Thrigonosomone $\mathrm{A}$ is an anthranol derivative and possesses a novel seven-membered cyclic anhydride moiety ( $\mathrm{Hu}$ et al., 2009). Glymontanine $\mathrm{A}$ is a flavonoid with a sulfur-containing amide moiety (Wang et al., 2005). Indeed, glymontanine A can be classified to be an alkaloid as well by the definition of alkaloids - "any of a class of naturally occurring organic nitrogen-containing bases" (https://www.britannica.com/science/alkaloid). So is hostasinine A (Figure 1). Hostasinine A is a benzylphenethylamine that is conventionally recognized as an alkaloid. This alkaloid - an organic amine - contains a rearranged carbon skeleton and a nitrone moiety (Wang et al., 2007b).

Many more novel organic amine-type alkaloids have been unveiled by the Hao laboratory (Figure 1), e.g., $\alpha$-myrifabrals A and B, $\beta$-myrifabrals A and B (Cao et al., 2014b), myritonines $\mathrm{A}-\mathrm{C}$ ( $\mathrm{Li}$ et al., 2016a), myrifabine (Cao et al., 2014a), and myriberine A (Huang et al., 2013) isolated from Myrioneuron faberi and M. tonkinensis (Rubiaceae). Myrifabrals and myritonines possess a novel cyclohexane-fused octahydroquinolizine and $N$-heterohexacyclic skeleton, respectively. Though all are lysine-derived alkaloids (Gravel and Poupon, 2010), these alkaloids are neither Myrioneuron alkaloids nor tripiperidine alkaloids except for myrifabine and myriberine A. Indeed, myrifabine is a hetero-dimer containing myritonine A (red) and dehydroschoberine (green) moieties. Dehydroschoberine is a typical tripiperidine alkaloid. So is myriberine A. Additionally, myritonine $\mathrm{C}$ represents a unique trans-decahydroquinoline motif and possesses a rare cyano functionality. Both myritonine $\mathrm{C}(\mathrm{Li}$ et al., 2016a) and myriberine A (Huang et al., 2013) showed inhibitory activity against hepatitis $\mathrm{C}$ virus.

Indole alkaloids are a large family of amino acid-tryptophan-derived bases. Strynuxlines A and B (Figure 1), with an unprecedented 6/5/9/6/7/6 hexacyclic ring system, are two novel indole alkaloids isolated from the seeds of Strychnos nux-vomica (Fu et al., 2012). These two are also monoterpenoid indole alkaloid since one of their building blocks is monoterpene. Catharoseumine from Catharanthus roseus is a new monoterpenoid indole alkaloid possessing a unique peroxide bridge moiety (Wang et al., 2012), the same as that of hedychins A and B (Zhao et al., 2018b), and artemisinins (Artemisinin Structure Research Collaboration Group, 1977). Tryptophan itself can be dimerized to afford alkaloids, as seen in trigonoliimines $\mathrm{A}-\mathrm{C}$ that are dimeric derivatives of tryptamine (Figure 1) (Tan et al., 2010).

Many alkaloids are not directly derived from amino acids. Moreover, the origins of the amines of many alkaloids are uncertain, such as that of Daphniphyllum alkaloids. Daphniphyllum alkaloids are the characteristic natural products of the genus Daphniphyllum (Daphniphyllaceae). This genus has about 30 species mainly distributed in Southeast Asia. There are 10 species in China, mainly distributed in several south provinces. Among them, Daphniphyllum calycinum 


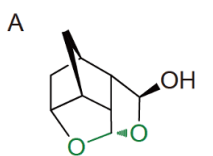

daphniacetal A<smiles>CC1(C)CCC[C@]2(C)C1OO[C@]1(C)O[C@H](c3ccoc3)[C@@H](O)C12</smiles>

hedychin A

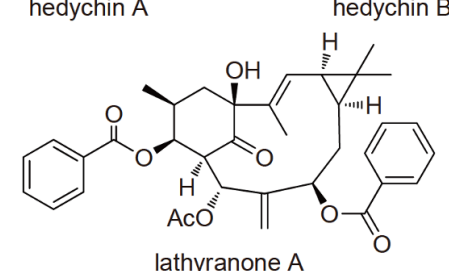

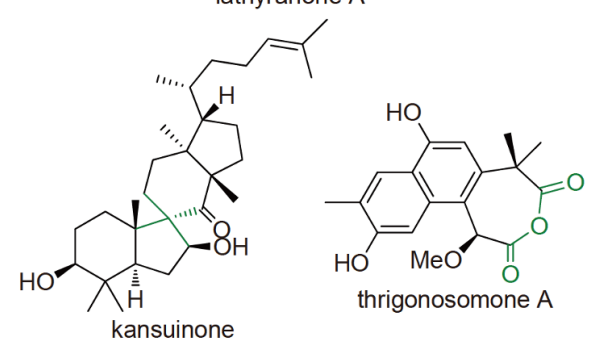

kansuinone

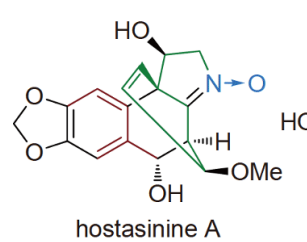

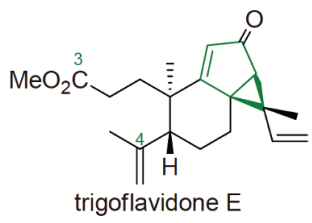<smiles>CC1CCCC2(C)C1OO[C@H]1OC(c3ccoc3)C(O)C12</smiles>

hedychin B

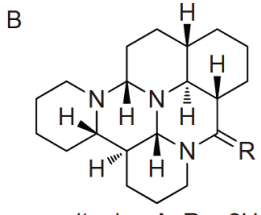

myritonine $\mathrm{A} \mathrm{R}=2 \mathrm{H}$ myritonine $\mathrm{B} \mathrm{R}=\mathrm{O}$

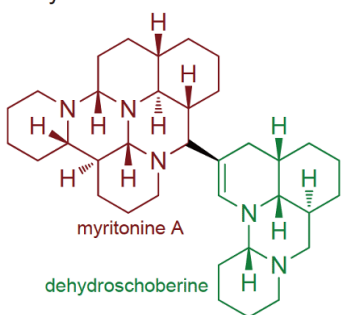

myrifabine

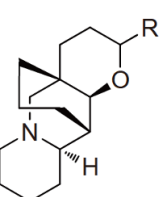

$\alpha$-myrifabral A $\mathrm{R}=\alpha-\mathrm{OH}$

$\beta$-myrifabral A R $=\beta-\mathrm{OH}$

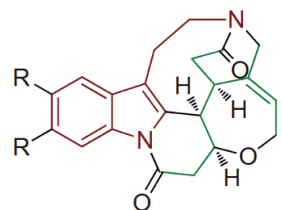

strynuxlines $\mathrm{A} \quad \mathrm{R}=\mathrm{OMe}$ strynuxlines $B \mathrm{R}=\mathrm{H}$
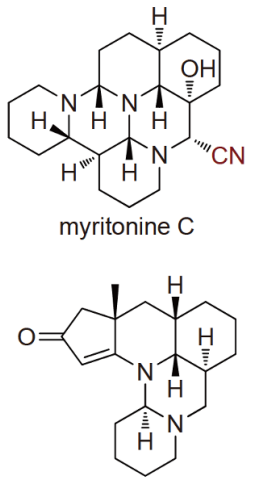

myriberine A

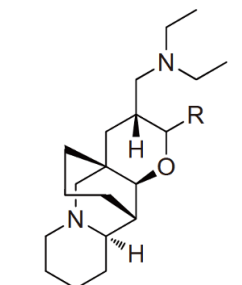

$\alpha$-myrifabral B R $=\alpha-\mathrm{OH}$

$\beta$-myrifabral $B \mathrm{R}=\beta-\mathrm{OH}$

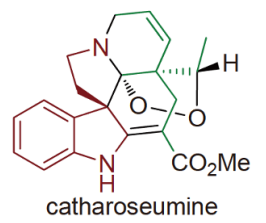

catharoseumine

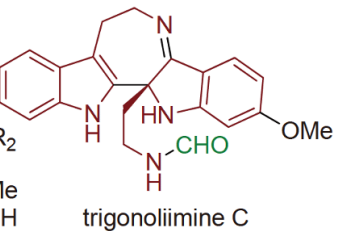

Figure 1 Structures of selected plant natural products reported by the Hao laboratory.

(Niu Er Feng), D. macropodum (Jiao Rang Mu) and D. oldhami (Hu Pi Nan) are used as medicinal plants for the treatment of asthma, cough, rheumatism, inflammation, fever and snake venom.

The study of Daphniphyllum alkaloids began in 1909. In 1996, Yamamura et al. determined the structure of the first Daphniphyllum alkaloid by single crystal X-ray diffraction analysis. Since then, their peculiar, changeable and complex polycyclic structure skeletons, unique biogenic synthesis pathways, biomimetic synthesis and synthesis methods, immediately become a research hotspot of natural product chemistry and organic synthesis in the world. With the development of 2D NMR technology and the comprehensive application of various methods of isolation and identification, more than 320 alkaloids with many novel skeletons have been isolated from this genus (Chattopadhyay and Hanessian, 2017).

In 1993, the Hao laboratory reported the first new structure of Daphniphyllum alkaloids, calycinine A, in China (Hao et al., 1993) (Figure 2). Since 2005, this laboratory has carried out studies on the alkaloid composition of seven species collected from different locations and different parts of the domestic Daphniphyllum plants, and successively isolated and identified about 100 new alkaloids including 17 new skeleton types (Figure 2). Longeracinphyllins A and B (Di et al., 2006b), and calycilactone A (Di et al., 2006a) contain a hexahydropyridine moiety that could be formed through the rearrangement of either the ring-B/-C or ring-A/-B. Longeracinphyllin B is the first F-ring-opened Daphniphyllum alkaloid that was confirmed by single crystal X-ray diffraction analysis, while calycilactone A has the E-ring-opened. Indeed, a putative oxidative rearrangement of the ring-B/-C of calycinine A may produce the 4-membered ring in calydaphninone (Di et al., 2007). Part of the NMR signals of calydaphninone are broadened or not observable due to a rapid conformation isomerization. This isomerization can be 
stabilized by aqueous acids, thus the NMR signals become normal. This method has been used widely in structure determinations of conformationally unstable Daphniphyllum alkaloids. Many more structure diversity of Daphniphyllum alkaloids can be attributed to the ring-A/-B variations (Figure 2), e.g., in that of daphmalenine A (Zhang et al., 2011), daphlongeranine A (Li et al., 2007a), daphnilongerine (Li et al., 2006) and daphlongamine A (Li et al., 2008a). Additionally, daphlongeranine $\mathrm{A}$ is the first one with a furan ring structure fragment (in green), daphnilongerine is the first one containing the western five-membered ring (in green), forming a novel pentacyclic skeleton, and daphlongamine $\mathrm{A}$ is the first one having $\mathrm{C}-24 / \mathrm{C}-10$ linkage (Figure 2).

The structure of daphhimalenine $\mathrm{A}$ is unique in that it lacks the $\mathrm{C}-21$ methyl group and ring-A/-B/-C compared to that of calycinine $\mathrm{A}$, which may be formed from a precursor via a decarboxylation carbon cation rearrangement (Zhang et al., 2009b). Longphyllineside A has a novel fused-decacyclic skeleton that was probably formed by a Diels-Alder cycloaddition between the alkaloid and an iridoid via an asynchronous concerted mechanism (Di et al., 2014). Daphenylline is the first example among Daphniphyllum alkaloids which has a tetra-substituted phenyl group fused with other three rings to form a multicyclic system (Zhang et al., 2009a). Oldhamine A is an zwitterion of cyclopentadienyl anion and tertiary amine cation, which is uncommon in natural products (Figure 2) (Tan et al., 2008).

\section{From chemotaxonomy to phytochemical geography}

Plant taxa are characterized not only by morphological features, but also by the presence or absence of typical natural products, which brought up chemotaxonomy - the classification of plant species by comparative analysis of their natural products. By comparing the diterpene alkaloids of 52 species on the basis of systematics, morphological evolution and geographical distribution, Hao, et al. studied the chemotaxonomy of the genus Aconitum L. (Ranunculaceae) and put forward the evolution of plant natural products - during evolution, a chemical diversification has taken place under the pressure of surrounding environment (Hao et al., 1985). Subsequently, the Hao laboratory discovered that only the complex of Spiraea japonica L. f. contained diterpenes and diterpene alkaloids among the more than 100 species of the genus Spiraea. This unusual phenomenon prompted him to select the Spiraea japonica complex (including one original species and eight varieties) to carry out further research. For the first time, he found the intrinsic correlation rules of plant geographical distribution, chemical composition and phylogeny, that is, geographical distribution may promote plant polyploidization, and plant polyploidization may promote the evolution of plant natural product biosynthesis, thus improving the environmental adaptability of producer plants (Hao, 2009).

Spiraea japonica L.f. shows strong morphological variability in leaf sizes and shapes. Except for Spiraea japonica var. japonica that is an introduced-horticultural species, eight varieties are distributed in Yangtze River Basin from west to east including S. japonica var. acuminata Franch., S. japonica var. acuta Yu, S. japonica var. acuminate Franch., $S$. japonica var. fortunei (Planchon)Rehd., S. japonica var. glabra (Regel)Koidz., S. japonica var. incisa Yu, S. japonica var. ovalifolia Franch., S. japonica var. pinnatifida Yu, and $S$. japonica var. stellaris Rehd. These nine intraspecific varieties formed a species complex. All seven varieties are distributed in Yunnan except for S. japonica var. pinnatifida Yu distributed in Southeast of Tibet (Zhang et al., 2006).

$S$. japonica complex plants are rich in diterpene alkaloids. Diterpene alkaloids are the characteristic natural products of the genera Aconitum, Delphinium and Consolida (Ranunculaceae), and are only occasionally reported in other genera and families. The Hao laboratory found that the Spiraea complex contains abundant diterpene alkaloids that can be classified into atisine- and hetisine-type, and only atisane-type diterpenes (Figure 3). The chemical composition studies on this complex began in the 1960s. The first study from China was reported in 1986 by Fang (Fang et al., 1986). In 1987, the Hao laboratory started the chemical study on Spiraea complex. This laboratory reported 44 new alkaloids and 11 diterpenes with the corresponding skeletons (Hao, 2009; Hao et al., 2003), and found an intimate relationship between structure types of diterpenes and alkaloids, and geographical distributions of the Spiraea complex plants (Table 1). Specifically, except for the Spiraea complex, neither diterpenes nor diterpene alkaloids were isolated from the plants of the genus Spiraea. However, there is one exception that the hetisine-type alkaloids were isolated from S. fritschiana var. parvifolia (Li et al., 1999). In view of the taxonomy confusion between the Spiraea complex plants and other species of the genus Spiraea, S. fritschiana var. parvifolia was supposed to be a variety of $S$. japonica, which is worthy of further verification.

There were only the hetisine-type alkaloids, but not the atisine-type alkaloids and diterpenes that have been isolated from the plants of Spiraea complex distributed in Guizhou and its east. The atisine-type alkaloids or diterpenes are the characteristic natural products of the plants of Spiraea complex distributed in northwestern and central Yunnan. Xuanwei district locates at the border between Yunnan and Guizhou. The plants of Spiraea complex collected in Xuanwei contains both atisine- and hetisine-type alkaloids (Table 1). In contrast, the plants collected from Tianmu mountain and Kuocang mountain of Zhejiang only contain hetisine-type alkaloids. The plants collected in Tengchong, a 


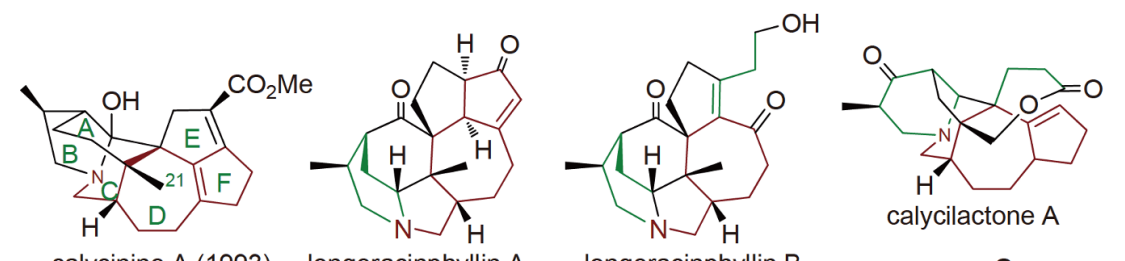

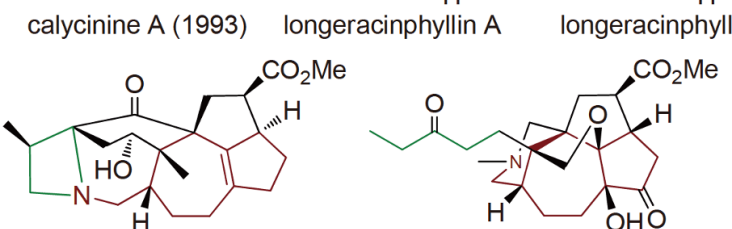
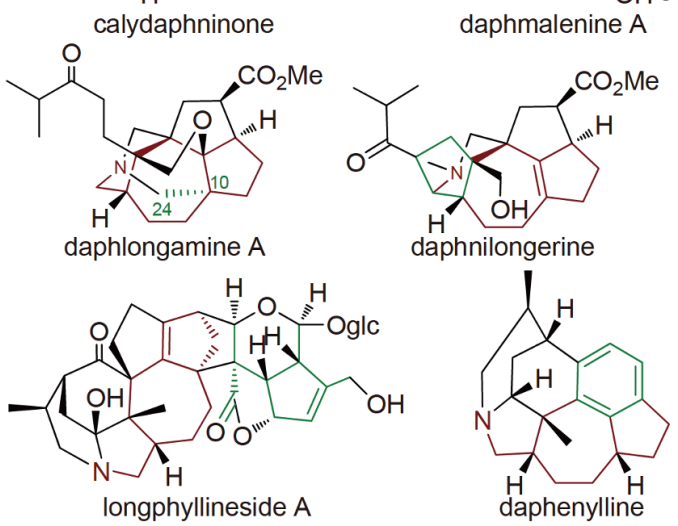

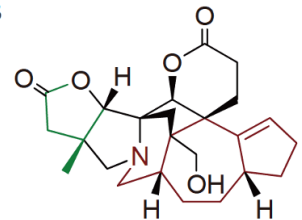

daphlongeranine $\mathrm{A}$
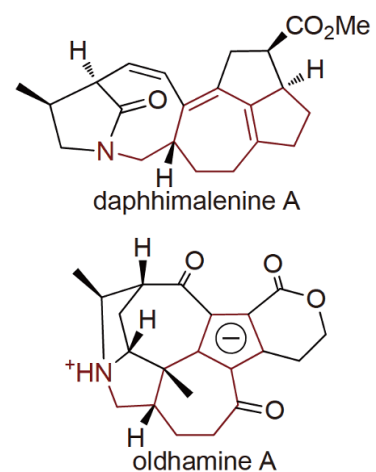

Figure 2 Structures of selected novel Daphniphyllum alkaloids reported by the Hao laboratory.

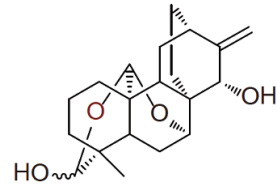

atisane-type

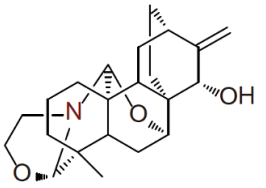

atisine-type

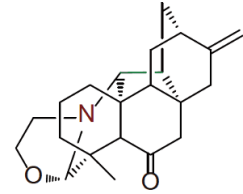

hetisine-type
Figure 3 Diterpene and diterpene alkaloid structure types of Spirarea complex.

western Yunnan area, only contain hetisine-type alkaloids, which is similar to that of the plants distributed in Guiyang, Guizhou. Overall, eastern populations of the Spiraea complex only contain hetisine-type alkaloids, and western populations contain both atisine-type alkaloids and diterpenes. One exception among the western populations is $S$. japonica var. fortunei distributed in Tengchong which only contains hetisine-type alkaloids (Table 1).

Interestingly, the ploidy levels of Spiraea complex are nicely correlated with the structure types of diterpenes and diterpene alkaloids (Table 1). Furthermore, the result from phylogenetic analysis is consistent with the chemical evolution of Spiraea diterpenes and diterpene alkaloids, i.e., from atisane-type diterpenes to atisine-type alkaloids to hetisine-type alkaloids. Chemical structure types indicate a close relationship between $S$. japonica var. glabra and $S$. japonica var. fortunei, which is further supported by the karyomorphological analysis, and that $S$. japonica var. for- tunei (tetraploid) may be evolved from $S$. japonica var. glabra (diploid) (Zhang et al., 2002). The facts that $S$. japonica var. fortunei distributed in Tengchong (western area) is tetraploid and contains only hetisine-type alkaloids would be attributed to that this population is a low altitude remnant at the western high mountain margin. The shift of chemical structure types reflects the response of the plants to the environment, incurring a striking phytochemical geographical feature for the Spiraea complex. This finding was recently supported by the study on Arabidopsis thaliana that the evolution of novel metabolic profiles not present in the parental diploids correlates with autopolyploidization (Vergara et al., 2017).

\section{Discovery of plant natural product pesticides on the basis of plant chemical defense}

Whether the interactions between host plants, and viral and microbial pathogens make these pathogens avirulent or virulent is usually proposed to be determined by the genefor-gene relationships, with a host gene for resistance corresponding to a pathogen gene for virulence. However, from the viewpoint of plant natural products, there is much more than a gene-for-gene mechanism in plant-pathogen interactions. Chemical ecology has documented tremendous examples of plant repelling pathogens using natural product 
Table 1 Correlations of the diterpenes, diterpene alkaloids, karyomorphology and geographical distributions of the Spiraea complex

\begin{tabular}{|c|c|c|c|c|c|}
\hline Plants & $\begin{array}{l}\text { Atisane-type } \\
\text { diterpenes }\end{array}$ & $\begin{array}{l}\text { Atisine-type } \\
\text { alkaloids }\end{array}$ & $\begin{array}{l}\text { Hetisine-type } \\
\text { alkaloids }\end{array}$ & Ploidy levels & $\begin{array}{l}\text { Sampling areas } \\
\text { (from west to east) }\end{array}$ \\
\hline var. acuta & 4 & 17 & 0 & $2 X$ & Lijiang, Yunnan \\
\hline var. incisa & 1 & 5 & 0 & $2 \mathrm{X}$ & Dali/Weixi, Yunnan \\
\hline var. stellaris & 1 & 8 & 0 & $2 X$ & Kunming, Yunnan \\
\hline var. acuminate & 1 & 17 & 0 & $2 \mathrm{X}$ & Kunming, Yunnan \\
\hline var. ovalifolia & 0 & 13 & 0 & $2 \mathrm{X}$ & Songming, Yunnan \\
\hline var. glabra & 0 & 3 & 8 & $2 X$ & $\begin{array}{c}\text { Xuanwei, Yunnan; } \\
\text { Tianmu/Kuocang mountains, Zhejiang }\end{array}$ \\
\hline var. fortunei & 0 & 0 & 20 & $4 X$ & Guiyang, Guizhou; Tengchong, Yunnan \\
\hline var. japonica & 0 & 3 & 5 & $2 \mathrm{X}$ & Japan; Russia \\
\hline
\end{tabular}

weapons. Our objective is the discovery of plant natural products of resistance. Since 2002, Hao has proposed that "low-toxic plant natural products may have a role in chemical defense for the producer plants against viruses", and subsequently found five plant $\mathrm{C}_{21}$-steroidal inhibitors against alpha-virus-like positive-strand RNA viruses from the medicinal plants Strobilanthes cusia and Cynanchum paniculatum (Li et al., 2007c). Since then, over 20 structure types of plant-origin pesticide lead compounds have been discovered in the Hao laboratory with the potential for the development of plant resistance against viruses and microbial pathogens.

\section{Anti-viral plant $C_{21}$-steroids}

Plants have evolved constitutive and inducible defense mechanisms by producing a vast array of natural products against various microbial pathogens. Many herbaceous plants have been used in traditional Chinese medicine to treat viral infectious diseases. It is conceivable that antiviral natural products would occur in plants as part of their innate defense arsenal. The vast assortment of natural products should serve as a large pool for screening for previously undescribed antiviral agents with a selective target spectrum and nontoxic to the host plants.

The investigation uncovered that seco-pregnane steroid glaucogenin $\mathrm{C}$ and its glycosides effectively and selectively inhibited alpha-virus-like positive-strand RNA viruses including plant-infecting tobacco (Nicotiana tabacum) mosaic virus (TMV), animal-infecting Sindbis virus (SINV), eastern equine encephalitis virus, and Getah virus, yet showed no evident toxicity to host cells. Using TMV and SINV as models, the study on the mechanism of action revealed that these plant $\mathrm{C}_{21}$-steroids predominantly suppressed the expression of sgRNA without affecting the accumulation of viral genomic RNA, indicating that these compounds selectively target the viral sgRNA expression machinery (Figure 4). Their potent in vitro and in vivo anti-alpha-like virus activity makes them lead candidates for the develop- ment of antiviral drugs to prevent alphavirus superfamily and other positive-strand RNA viral infections in humans and in plants. In conclusion, this work suggests that sgRNAs may be a tempting target for antiviral therapy. These results pave the way for the discovery of more potential antiviral compounds from plant sources (Li et al., 2007c).

\section{Development of biological pesticides on the basis of plant systemic acquired resistance}

Plant systemic acquired resistance (SAR) is a major characteristic of plant resistance to pathogen infection, i.e., plants are induced by some biological or abiotic stimulators (elicitors) to produce new, broad-spectral systemic resistance, and obtain strong resistance to infections. This acquired resistance can be extended to the whole plant, and lasts for several weeks or months. Since the first discovery in the 1980 s, SAR activators, including the original biological inducers and the current various synthetic inducers, have become a mainstream in the development of biological pesticides in the 21 st century. The known SAR inducers mainly include salicylic acid (SA), 2,6-dichloroisonicotinic acid (DCINA) (Ward et al., 1991), and benzothiadiazole (BTH) (Görlach et al., 1996). Acibenzolar-S-methyl (ASM), a BTH derivative was commercialized (Oostendorp et al., 2001). Additionally, ningnanmycin, a bio-source cytosine nucleoside derivative, has been developed for agrochemical and pesticide in China (Xiang et al., 1995).

In the course of growth and development, plant defense system and chemical defensive substances are indispensable weapons in their competition with the environment or other organisms, which is the result of long-term evolution and natural selection. Chemical inducers, such as SA and jasmonic acid, are included in the defense substances produced by plants under stress conditions. However, the presence of chemical inducers with defensive effects on other species in the inherent chemical composition of plants is rarely reported. With this scientific question, the Hao laboratory has 


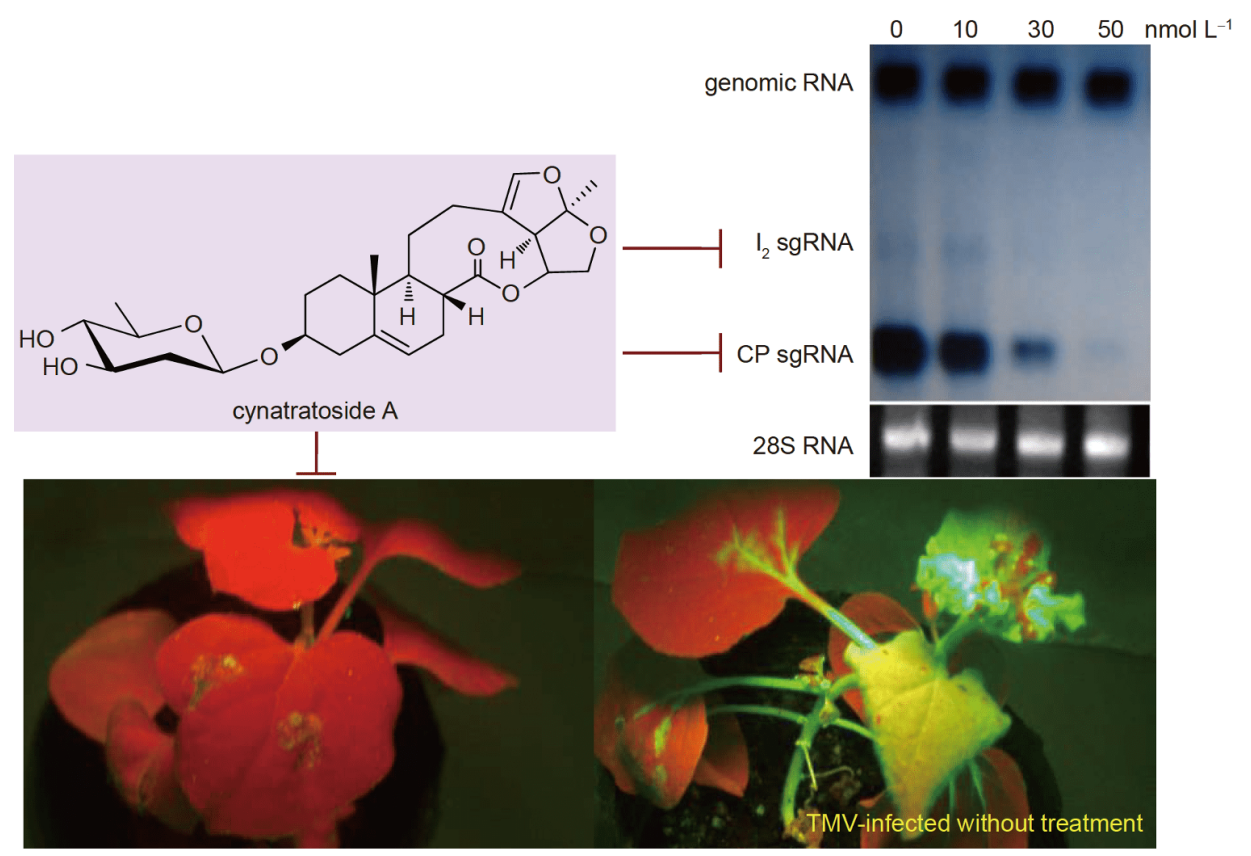

Figure 4 The $\mathrm{C}_{21}$-steroid cynatratoside A inhibits TMV through downregulating its subgenomes in Nicotiana tabacum leaves.

carried out research on plant natural product inducers and made important progress.

\section{AHO is a potent activator of induced-plant SAR and ef- fective to a broad range of plant diseases}

We provide the first demonstration of a natural product inducer of SAR. This interesting example is represented by 3acetonyl-3-hydroxyoxindole (AHO), which was isolated from extracts of the antiviral traditional Chinese medicine $S$. cusia and found to induce resistance in plants to a broad range of diseases. During resistance induction, AHO itself triggers PAL activity, elevates the SA level and induces $P R-1$ gene expression in $N$. tabacum plants. These results suggest that AHO is an effective activator of induced-plant SAR by triggering SA biosynthesis and signaling. AHO induces SAR by triggering signaling upstream of SA accumulation in $N$. tabacum and Arabidopsis plants but not in nahG transgenic mutants. Additionally, AHO-induced upregulations of ribosome-inactivating proteins (RIP1/2) were revealed to be critical for the SA-independent anti-TMV activity (Figure 5). Together, these results demonstrate that AHO is an effective inducer of plant SAR activation via the SA-mediated signal transduction pathway. These findings may enhance the understanding of the pathway(s) leading to multiple disease resistance and provide new opportunities for the control of microbial diseases in plants ( $\mathrm{Li}$ et al., 2008b). The Hao laboratory also has carried out a large-scale synthesis and safety evaluation for the new chemical activator AHO. The field test for consecutive years achieved significant antiTMV effects. In the last three years, the efficacy of appli-

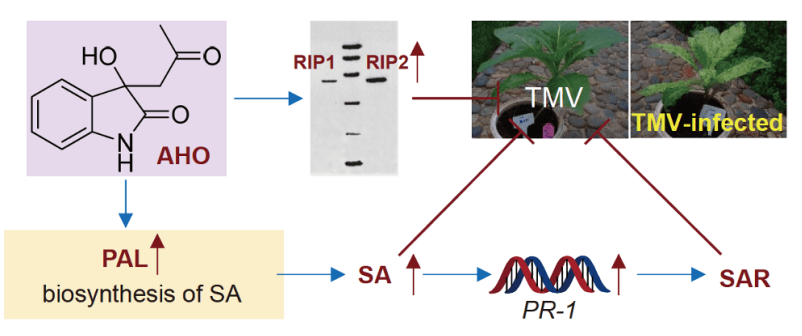

Figure 5 AHO induces systemic acquired resistance and inhibits TMV in Nicotiana tabacum.

cation demonstration has reached more than $75 \%$ in prophylaxis and treatment of mulberry powdery mildew disease caused by Phyllactinia guttata.

\section{Limonoids activate plant SAR and inhibit TMV}

Limonoids are a family of highly oxygenated-triterpenoids that lost the terminal four-carbon of the side chain with the remaining four-carbon cyclized into a furan ring, and thus are classified to be tetranortriterpenoids (Liu et al., 2014; Wang et al., 2006). The name limonoid was derived from the bitter component, limonin, isolated from citrus fruits. Limonoids have a broad range of bioactivities including insecticidal, antibacterial, antifungal, antimalarial, and antiviral, but are best-known as insect antifeedants, e.g., azadirachtin from the neem tree (Fang et al., 2011; Tan and Luo, 2011). Recently, aphanamixoid A, a novel skeleton limonoid that may be derived from an analogy of aphanamixoid B via 3,3-rearrangement (Figure 6), was found to be a potent antifeedant against Helicoverpa armigera (Cai et al., 2012). 

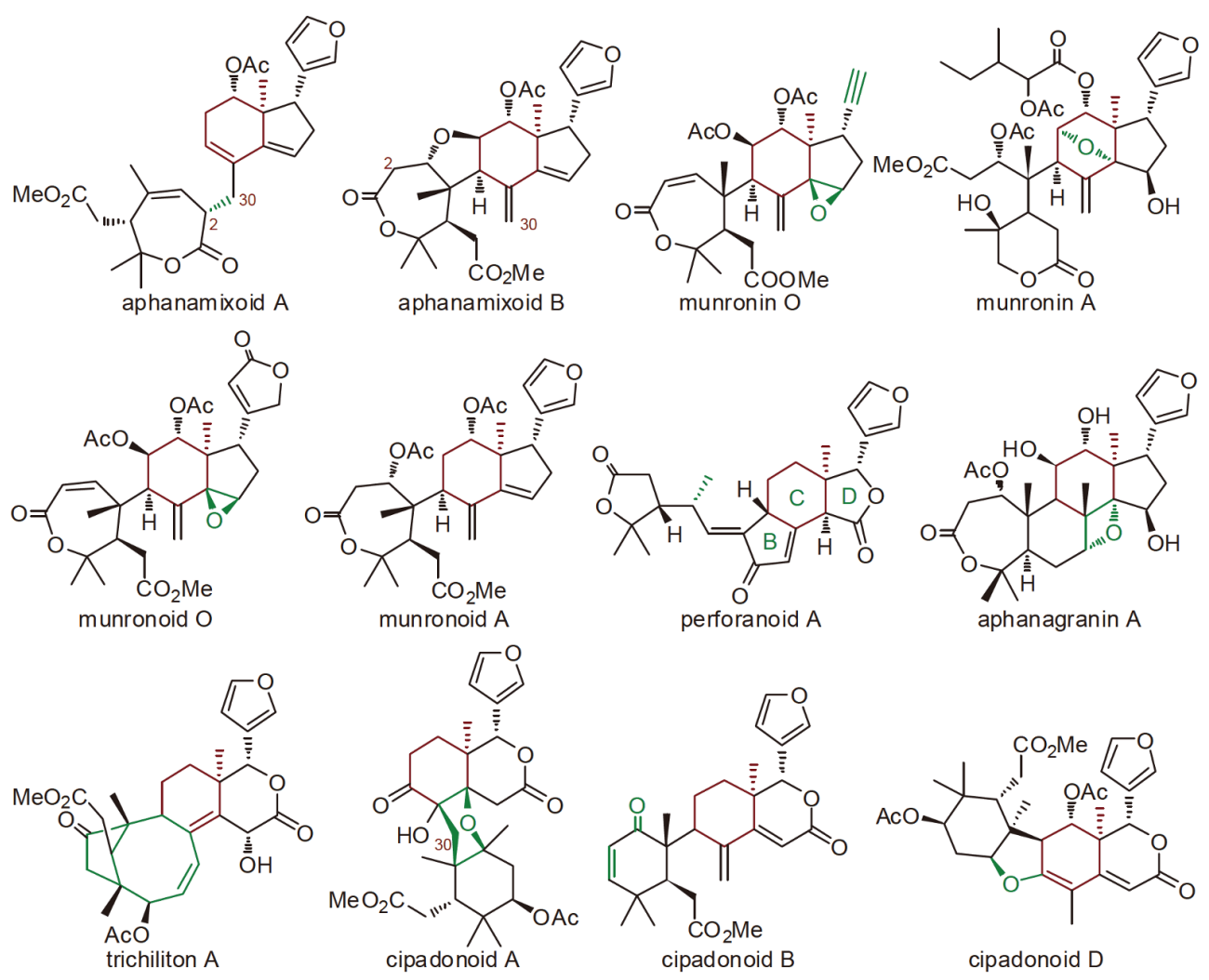

cipadonoid D

Figure 6 Structures of selected novel limonoids reported by the Hao laboratory.

For the first time, the Hao laboratory reported that some limonoids are potent activators of plant-induced SAR. In $N$. tabacum plants, munronin $\mathrm{O}$ showed remarkable protective activity against TMV infection compared with that of ningnanmycin. In particular, munronin $\mathrm{O}$ decreased the accumulation of TMV coat protein (CP) and TMV CP gene expression in the lower leaves and newly grown leaves on the 3rd and 7th day post-treatment, respectively, and thus inhibited TMV infection through a systemic resistance. The activities of induced resistance-related enzymes including PAL, POD, SOD and PPO were induced by munronin O treatment, and further enhanced by the munronin O+TMV treatment. Additionally, munronin $\mathrm{O}$ increased salicylic acid content in TMV-infected $N$. tabacum leaves. These results indicated that munronin $\mathrm{O}$ inhibited TMV through inducing N. tabacum plant SAR (Yan et al., 2018). The ethynyl group is a noteworthy structure novelty of munronin O. Alkynyl groups are rare in natural products. However, those with alkynyls usually show potent bioactivity. This may be critical to the anti-TMV and SAR activation activity of munronin $\mathrm{O}$ because munronin $\mathrm{O}$ is the most potent one among this series of munronins A-V (Yan et al., 2015). It was suggested that the epoxy group is indispensable to the bioactivity of munronin $\mathrm{O}$ as well, which was supported by the observation that munronoid $\mathrm{O}$, an epoxy limonoid among munronoids $\mathrm{A}-\mathrm{O}$, showed stronger anti-TMV activity than the positive control ningnanmycin (Ge et al., 2012a; Ge et al., 2012b).

The structure-activity relationship of limonoids for the SAR is worthy of further study because the structural diversity of the limonoid family is tremendous. Perforanoid A is a novel limonoid in that it contains a novel BCD tricyclic ring system (Figure 6). Its structure, including the stereochemistry at C-10, was confirmed by total synthesis ( $\mathrm{Lv}$ et al., 2016). Aphanagranin A possesses an oxetane ring (Figure 6) (Tong et al., 2012) that is only observed in several natural products, e.g., taxol (Guerra-Bubb et al., 2012). Trichiliton $\mathrm{A}$ is a rearranged limonoid with a [5.2.1]bicyclodecane ring system (Fang et al., 2010). Harrpenoid B has a rearranged spirocyclic moiety (Yan et al., 2011). Cipadonoid $\mathrm{A}$ is a novel limonoid with a rearranged tetrahydropyranyl ring $\mathrm{B}$ containing an unusual C-30 exomethylene from leaves of Cipadessa cinerascens (Fang et al., 2008). From the same plant, six more new limonoids, namely cipadonoids $\mathrm{B}-\mathrm{G}$ belonging to rings B,D-seco-type, were isolated (Figure 6) (Fang et al., 2009).

\section{Miscellaneous anti-TMV plant natural products and SAR inducers}

Triterpene saponins are a large family of plant natural products with diverse bioactivities (Osbourn et al., 2011). Cinchonaglycoside C (Figure 7) is an anti-TMV triterpene 


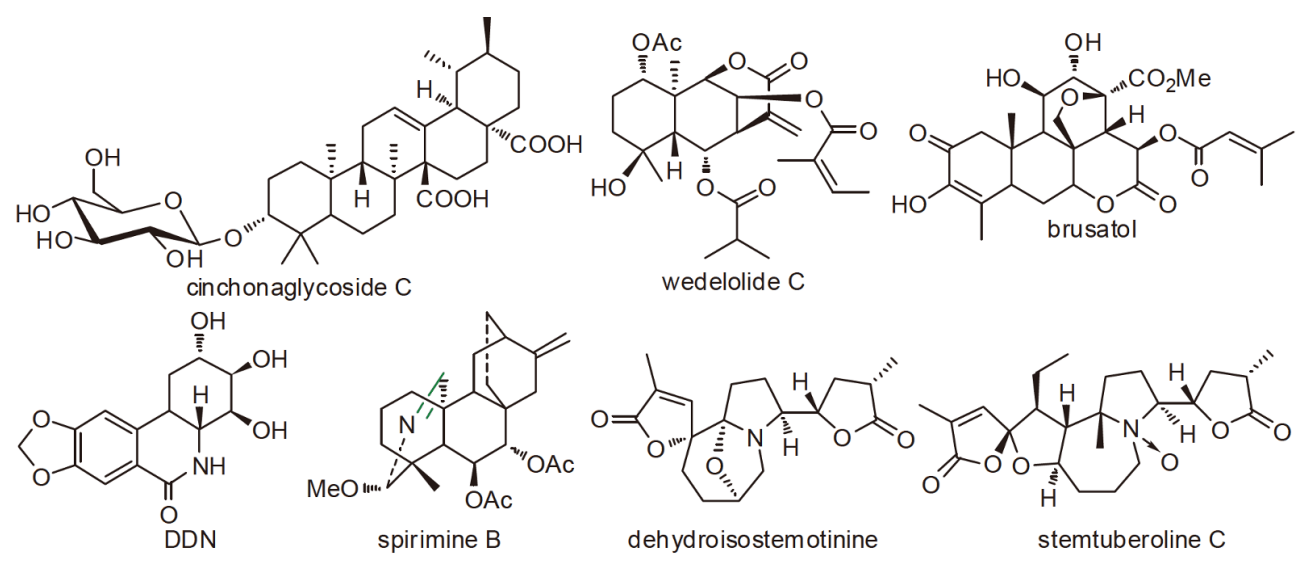

Figure 7 Structure of selected anti-TMV plant natural products.

saponin isolated from S. cusia through bioactivity-guided fractionation ( $\mathrm{Li}$ et al., 2007b). The Hao laboratory further determined that cinchonaglycoside $\mathrm{C}$ induced the production of CIP31, a new ribosome-inactivating protein (RIP) with the molecular weight of $31-\mathrm{kD}$, in $N$. tabacum leaves. CIP31 inhibited the synthesis of coat protein (CP) of TMV, resulting in disrupting the long distance movement and multiplication of TMV in N. tabacum plants. Moreover, CIP31 was only synthesized with cinchonaglycoside $\mathrm{C}$ treatment, indicating that it is SA-independent SAR inducer.

Wedelia trilobata (L.) Hitchc. is an invasive weed in China, and has a strong allelopathic activity on neighboring plants. The Hao laboratory found that wedelolide C (Figure 7) ( $\mathrm{Li}$ et al., 2013), one of the 10 sesquiterpene lactones isolated from $W$. trilobata, showed strong anti-TMV activity in the half-leaf assay that tests the antiviral activity through measuring the local lesion infected by TMV on the leaf of Nicotiana glutinosa (Yan et al., 2010). Further study indicated that wedelolide $\mathrm{C}$ evidently activates PAL at $0.01 \mu \mathrm{g} \mathrm{m}^{-1}$ and thus is a strong SAR inducer ( $\mathrm{Li}$ et al., 2013).

Using the half-leaf method (Yan et al., 2010), the Hao laboratory found that all the 17 quassinoids isolated from Brucea javanica (L.) Merr. showed evident anti-TMV activity. Further study indicated that some quassinoids including brusatol (Figure 7) not only inhibited the accumulation of TMV coat protein but also enhanced the host plant's resistance to TMV infection (Yan et al., 2010). Quassinoids are the characteristic natural products of the family Simaroubeacea, and more than 400 quassinoids have been reported (Yang et al., 2020). These anti-TMV quassinoids may have the potential of becoming lead compounds.

Among 17 benzylphenethylamine alkaloids of five skeleton-types, 7-deoxy-trans-dihydronarciclasine (DDN) (Figure 7) was identified to be the most potent one in inhibiting TMV in the half-leaf method using ribavirin as the positive control (Wang et al., 2007a). Spiraea atisine-type alkaloids with an imine group at C-20, e.g., spirimine B (Figure 7), showed more potential anti-TMV activity than that of others and the positive control ningnamycin (Figure 7) (Ma et al., 2016). Two dozens of alkaloids were isolated from the roots of Stemona tuberosa. Among them, dehydroisostemotinine (Hu et al., 2019) and stemtuberoline $\mathrm{C}$ (Hu et al., 2020) (Figure 7) showed strong anti-TMV activity.

\section{Chemical biology-driven innovative drug discovery}

Chemical biology advocates cross-disciplinary research at the interfaces of chemical and biological systems to disentangle chemical and biological complexity. The conception of chemical biology should fertilize natural product research because natural products are dedicatedly made by organisms with complex biological systems. The roles of natural products in their producers and their functions on other organisms are mostly unclear to human knowledge. In particular, using plant natural products as probes in mammalian systems, we can make new discoveries in search for both lead compounds and potential drug targets. For instance, celastrol is a major triterpene component of the traditional Chinese medicine Thunder God Vine used for the treatment of rheumatoid arthritis. Celastrol itself has various bioactivities including anti-inflammation and anticancer. Recently, Sang et al. found that celastrol showed fine-tuned specificity in activating inflammasomes in macrophages, underlying it serve as a useful chemical probe for interpreting inflammation mechanisms (Sang et al., 2018). The Hao laboratory has discovered a series of plant natural product probes. Next we describe several examples of modulating Wnt pathway, probing mitochondria and lysosomes.

\section{Plant natural product modulators of Wnt signaling}

Using a mammalian cell line-based reporter gene screening system, Li's and Hao's laboratories identified that the atisane-type diterpene lactone NC043 (Figure 8) inhibited 
Wnt3a- or LiCl-stimulated Top-flash reporter activity in HEK293T cells and the growth of colon cancer cell lines including SW480 and Caco-2. In SW480 cells, NC043 downregulated the expression of the Wnt target genes, including Axin2, Cyclin D1 and Survivin, and decreased the levels of corresponding proteins. Additionally, the protein levels of $\mathrm{Cdc} 25 \mathrm{c}$ and $\mathrm{Cdc} 2 \mathrm{~s}$ were decreased by $\mathrm{NC043}$ treatment too. However, NC043 did not change the cytosolnuclear distribution and total protein level of soluble $\beta$-catenin. The association of $\beta$-catenin/TCF4 was impaired by NC043 in SW480 cells. These results indicated that NC043 is a novel antagonist of Wnt signaling that functions downstream of $\beta$-catenin (Wang et al., 2011). The cellular target of $\mathrm{NC} 043$ was "fished" using biotinylated NC043 in biotinpulldown assay, and identified to be CARF protein by MS analysis, which was confirmed by knockdown experiments. Using competitive binding assay, NC043 was found to bind to CARF covalently. Mapping and site-directed mutations revealed that $\mathrm{NC} 043$ binds to the Cys516 residue of CARF probably through 1,4-addition between its Michael accepter and Cys516 thiol. Further, using NC043 as a chemical biology tool, CARF was determined to be a positive regulator of Wnt/ $\beta$-catenin signaling (He et al., 2017).

Subsequently, this collaborative team found that the plant natural product parthenolide (Figure 8), a sesquiterpene lactone isolated from Magnolia grandiflora L. (Wu et al., 2001), inhibits Wnt signaling by binding to RPL10 protein to downregulate the levels of TCF4/LEF1 proteins. RPL10 is a component of the $60 \mathrm{~S}$ ribosome. The use of parthenolide probe showed that deprivation of RPL10 decreased the levels of TCF4/LEF1 but had no effects on $\beta$-catenin levels, indicating a selectivity of the $60 \mathrm{~S}$ ribosome in regulating protein synthesis (Zhu et al., 2018).

Li's and Hao's laboratories used a cell-based highthroughput screening method and identified the small-molecule phenanthridine alkaloid HLY78 (Figure 8) as an activator of the Wnt/ $\beta$-catenin signaling pathway. HLY78 was verified to be a new "Wnt-specific" Wnt activator through binding to the DIX domain of Axin to promote the formation of the Axin-LRP6 complex (Wang et al., 2013). Furthermore, study on the structure-activity relationships revealed that triazole groups at C-8 and C-9 of phenanthridine compounds markedly enhanced Wnt activation. A C-11-C-12 single bond is also important for Wnt activation. Subsequently, two Wnt agonists, namely compounds 12 and 14 (Figure 8), were designed and synthesized. The results for these agonists indicated that the combination of a 4-ethyldihydrophenanthridine skeleton and a triazole substituent improves Wnt activation (Chen et al., 2016).

\section{Mitochondrium-targeted plant natural products}

The Bcl-2 family members regulate mitochondrial functions. Specifically, Bax/Bak proteins are well-known for promoting apoptosis by targeting the outer mitochondrial membrane (OMM) to induce the release of cytochrome c from the mitochondrial intermembrane space. Therefore, the Bax/Bakindependent cell apoptosis is of particular interest. Using the E1A/K-Ras-transformed $b_{a x}^{-/-} / b a k^{-/-}$MEF cell screening model, Chen's and Hao's laboratories identified the atisanetype diterpene lactone S-3 (Figure 8) that induced Bax/Bakindependent cell apoptosis and inhibited the tumor growth from these cells in mice. In the S-3-treated $b_{a x}^{-/} / b a k^{-/-} \mathrm{MEF}$ cells, the level of Bim protein was upregulated and translocated onto mitochondria where it interacts directly with Bcl2 to form oligomeric pores in the OMM in the absence of Bax and Bak, activating apoptotic signaling (Zhao et al., 2012). Further study identified that S-3 (Figure 8) bonded to the selenocysteine residue of the selenoproteins TrxR1 and TrxR2 and inhibited their antioxidant activity, which disrupted the cellular redox homeostasis and activated the FOXO3a protein. The activation of FOXO3a upregulates the Bim protein level in $b a x^{-/-} / b a k^{-/-}$MEF cells thus induces the Bax/Bak-independent cell apoptosis (Liu et al., 2013). 15Dehydroxy-15-oxospiramines C/D and 15-deacetoxy-15oxospiramine $\mathrm{S}$ (Figure 8 ) are semisynthetic derivatives of the spiramines $\mathrm{C} / \mathrm{D}$, atisine-type diterpenene alkaloids isolated from the Chinese herbal medicine Spiraea japonica
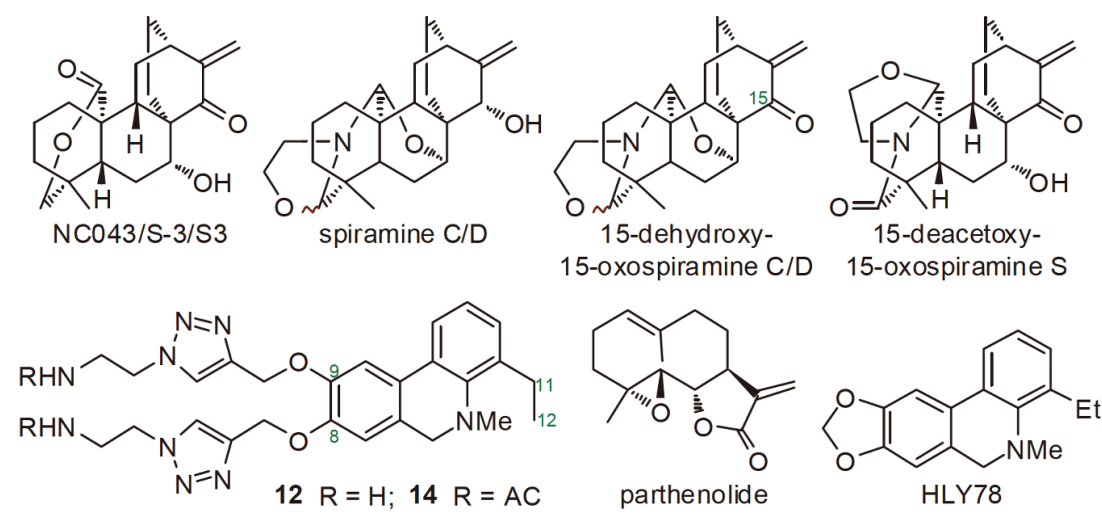

Figure 8 Structures of plant natural product Wnt modulators and mitochondrial inhibitors. 
complex. Both derivatives but not spiramines $\mathrm{C} / \mathrm{D}$ induced the apoptosis of $b a x^{-/-} / b a k^{-/-}$MEF cells, indicating that the Michael acceptor is necessary for the activity (Yan et al., 2014).

Cellular apoptosis and mitochondrial fusion are the most evident phenotypes induced by the atisane-type diterpene lactone S-3. The TrxR1/2/FOXO3a/Bim axis does induce apoptosis but is not responsible for mitochondrial fusion. Mitochondria are highly dynamic undergoing constant fission and fusion in cells. In mammalian cells, fusion is coordinated by the mitofusins (MFN) $1 / 2$ located on the OMM, and optic atrophy 1 (OPA1) located on the inner mitochondrial membrane (IMM). MFN1/2 and OPA1 are dynaminlike GTPases, and promote the fusion of the OMMs and the IMMs by GTP hydrolysis, respectively. Mitofusin protein levels are regulated both transcriptionally and with posttranscriptional mechanisms. Pulldown experiments with biotin-modified S3 indicated that S3 bound to the mitochondrially localized deubiquitinase USP30. Site-directed mutations revealed that S3 covalently bonded the C77 residue in the catalytic domain of USP30 through its Michael acceptor, resulting in an increase of the non-degradative polyubiquitinated Mfn1/2, which enhances the inter-mitochondrial interactions of Mfn1 and Mfn2 to promote mitochondrial fusion (Figure 9) (Yue et al., 2014).

\section{Lysosome-targeted plant natural products}

Lysosomes are specialized vesicles responsible for the digestion of macromolecules, old cell parts, and microorganisms. Lysosomes contain more than 60 hydrolytic enzymes, the activation of which requires an acidic environment maintained by ATP-dependent proton pumps. Lysosomal enzymes digest macromolecules, protecting the cell from self-degradation in case of lysosomal leakage or rupture. The lysosome also contains more than 100 membrane proteins. Research on the functions of lysosomal enzymes and membrane proteins has established lysosomes as key cellular metabolic hubs in a variety of cellular processes including nutrient sensing (Savini et al., 2019). Therefore, lysosome biogenesis is proposed to be an adaptive response to cellular stress and nutritional conditions.

How lysosome biogenesis responds to the signals other than nutrient supply is poorly understood. By monitoring the change of lysosome numbers in HeLa cells exposed to natural small-molecule compounds, Yang's and Hao's laboratories identified two diterpenoids, HEP14 and HEP15 (Figure 10), which induced lysosome biogenesis through the transcription factor TFEB, but not TFE3. They further found that HEP14 decreased the phosphorylation of TFEB and induced its nuclear translocation independently of mTORC1 inhibition, indicating that HEP14 and HEP15 did not activate the lysosomal nutrient-sensing machinery. Pulldown experiments with biotin-conjugated HEP14 revealed that HEP14 directly bound to $\mathrm{PKC} \alpha / \delta$, which was confirmed by the microscale thermophoresis. This binding increased the phosphorylation and lysosomal association of $\mathrm{PKC} \alpha / \delta$, which was attributed to the HEP14- and HEP15-induced TFEB dephosphorylation and nuclear translocation. However, the TFEB dephosphorylation was not induced by protein phosphatases. Using HEP14 as a probe, Yang and Hao discovered that $\mathrm{PKC} \alpha / \delta$ phosphorylation of GSK $3 \beta$ inhibited GSK3 $\beta$-mediated TFEB phosphorylation and lysosomal association of GSK3 $\beta$. This suggests that GSK3 $\beta$-catalyzed TFEB phosphorylation probably occurs on lysosomes. Moreover, HEP14, but not Torin1, induced the nucleus-to-

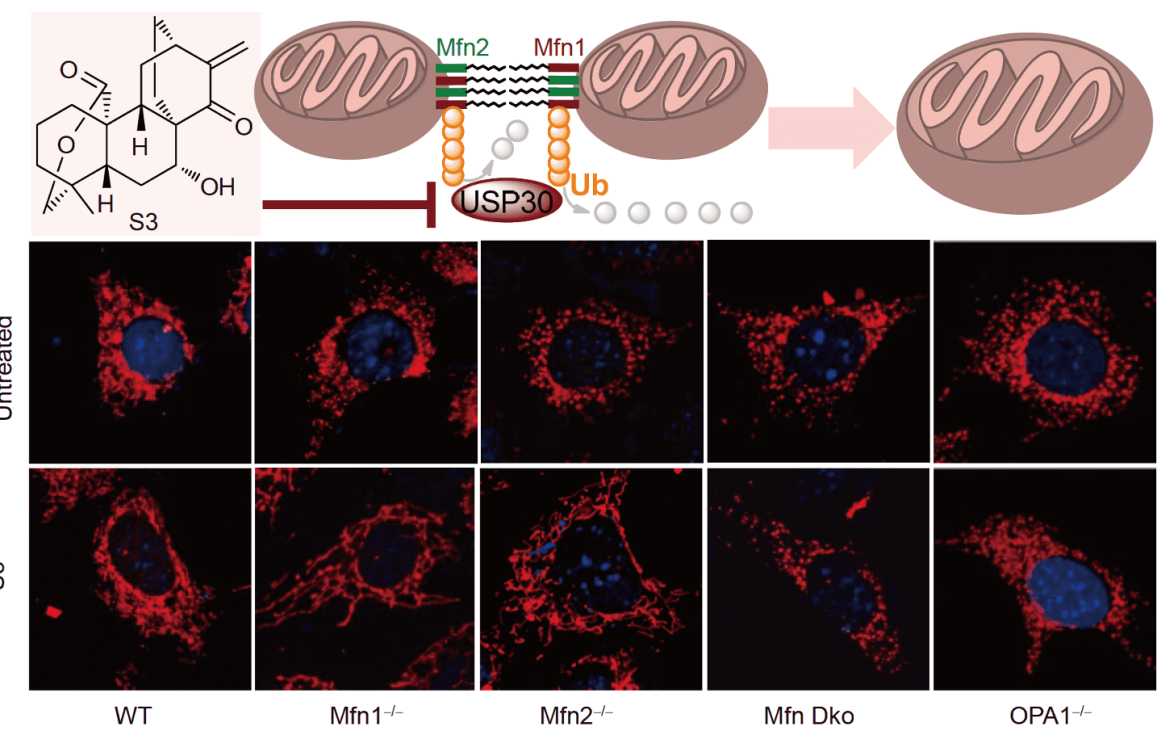

Figure 9 The atisane-type diterpene S3 promotes the mitochondrial fusions by inhibiting the deubiquitinase USP30 and upregulating the ubiquitination levels of MFN1/2 proteins. 

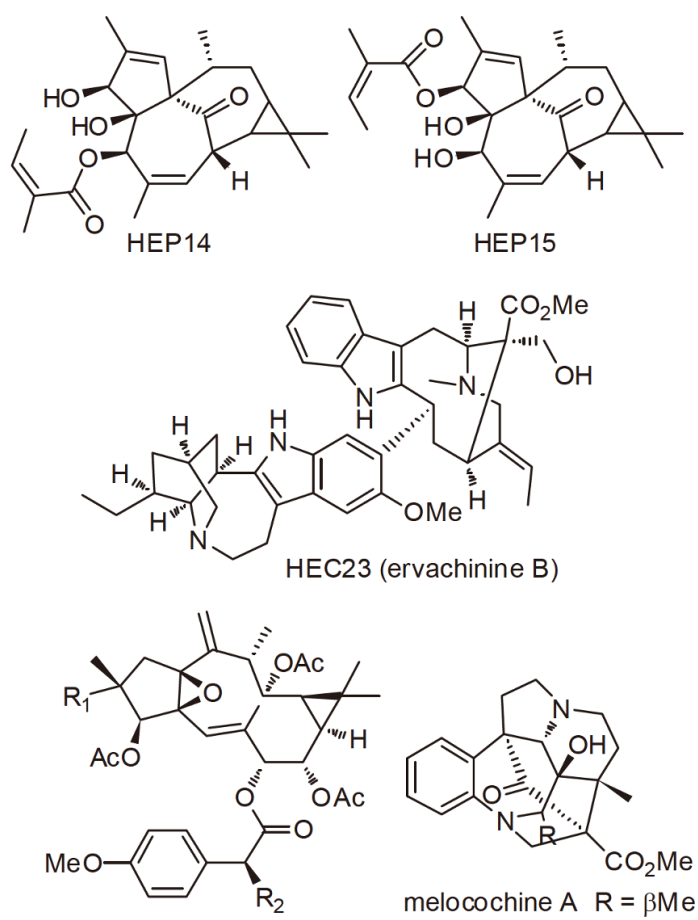

euphorblin $\mathrm{B} \mathrm{R}_{1}=\mathrm{H} \mathrm{R}_{2}=\mathrm{OH}$ euphorblin $\mathrm{D} \mathrm{R}_{1}=\mathrm{R}_{2}=\mathrm{OH}$

euphorbia factor RL4 $\mathrm{R}_{1}=\mathrm{R}_{2}=\mathrm{H}$

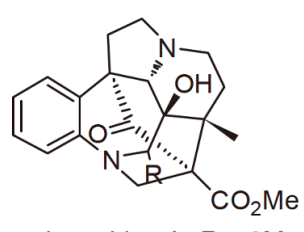

melocochine $A \quad R=\beta M e$ melocochine $B \quad R=\alpha M e$

Figure 10 Structures of lysosome biogenesis agonists or lysosome-damaging agents.

cytosol relocation of the transcriptional repressor of lysosome biogenesis ZKSCAN3, depending on the PKC-JNK2/ p38 axis rather than the $\mathrm{PKC} \alpha / \delta$-GSK3$\beta$ signaling. The cytoplasmic translocation of ZKSCAN3 consequently removes its repression on transcription of lysosomal and autophagic genes. HEP14-activated lysosomal biogenesis promotes lysosome-dependent clearance of protein aggregates and lipid droplets, providing a potential strategy for treatment of lysosome-related diseases (Li et al., 2016b).

Taking the visual advantage of the endolysosome system in coelomocytes of Caenorhabditis elegans, this collaborative team identified four bisindole alkaloids, which induced vacuolar enlargement in coelomocytes, from a screen of 257 plant natural compounds. Among them, the compound HEC23 (Figure 10) (Guo et al., 2012) showed the strongest effect in a time- and dose-dependent manner. Further, this team confirmed that HEC-23 induced the lysosomal enlargement and impaired lysosomal integrity, acidification and digestion capacity in a conserved manner. Of note, HEC-23 induced RIP1/3-independent necrosis, which was dependent on the STAT3 signaling and executed by the lysosomal endopeptidase cathepsins B and L (Li et al., 2018).

The use of $C$. elegans to screen lysosome-targeting plant natural products further identified three bioactive ingol-type diterpenoids, including the euphorblins B, D, and RL4 (Figure 10). These three compounds upregulated the ex- pression of the lysosomal genes, such as LAMP1 (lysosomalassociated membrane protein 1), CTSB (cathepsin B), CTSA (cathepsin A), and ATP6 (ATPase $\mathrm{H}^{+}$transporting V0 subunit E1) (Zhao et al., 2018a). In addition, two novel monoterpene indole alkaloids isolated from Melodinus cochinchinensis, melocochines A and B (Figure 10), were evaluated for inducing lysosomal biogenesis. Both compounds exhibited strong activities towards increasing the expression of the lysosomal genes, LAMP1, CTSB, CTSA, and ATP6 (Zhang et al., 2019).

\section{Plant natural product inhibitors of friend leukemia integration 1}

Friend leukemia integration 1 (Fli-1) is a transcriptional factor in regulating granulopoiesis, erythroid and megakaryocytic development, and a proto-oncogene in hematopoiesis by functioning as both transcriptional activator and repressor. Recently, using the luciferase reporter assay, BenDavid's and Hao's laboratories found two semisynthetic derivatives A661 and A665 (Figure 11) of the atisane-type diterpenoids downregulating Fli-1 protein level, increasing miR-145 level, and binding to the DNA-binding domain of the Fli-1 protein (Liu et al., 2019). These results are consistent with the inhibition of Fli-1 by A661 and A665 because Fli-1 and miR145 are reciprocally antagonized, i.e., Fli-1 can repress transcription of the primary transcript for miR145 (Riggi et al., 2010), and miR145 deficiency increases Fli-1 mRNA level (Kumar et al., 2011). Intriguingly, the increase of Fli-1 mRNA level was observed in A661and/or A665-treated HEL cells (Supplemental Figure 1 of Liu et al., 2019), indicating that miR145 may inhibit the translation of Fli-1 mRNA, or that A661 and A665 may inhibit ribosome as well.

Compounds A1544 and A1545 are two flavaglines that are flavonol-cinnamate-derived cyclopena $[b]$ benzofurans (Figure 11). Flavaglines, e.g., rocaglamide is a potent antileukemic agent (Lu King et al., 1982). However, the underlying mechanisms were not fully appreciated. Both A1544 and A1545 showed strong cytotoxicity against erythroleukemia (CB7, HEL), human myelogenous leukemia (K562), B-cell Burkitt lymphoma (Daudi), and multiple myeloma (MM.1S and RPMI8226) cell lines, respectively, and induced erythroid differentiation of leukemic cells through c-Raf-MEKMAPK/ERK signaling. In particular, these compounds reduced phosphorylation of eukaryotic translation initiation factor 4E (eIF4E), and inhibited Fli-1 protein synthesis that underlay their antileukemic effect (Song et al., 2018). Polycyclic polyprenylated acylphloroglucinols (PPAPs) are a large family of complex plant natural products having diverse bioactivities (Yang et al., 2018). Compounds (-)-garmultin C, (+)-garmultin $\mathrm{C}$ and $(-)$-garmultin $\mathrm{D}$ are novel PPAPs (Figure 11), and were evaluated of showing strong 

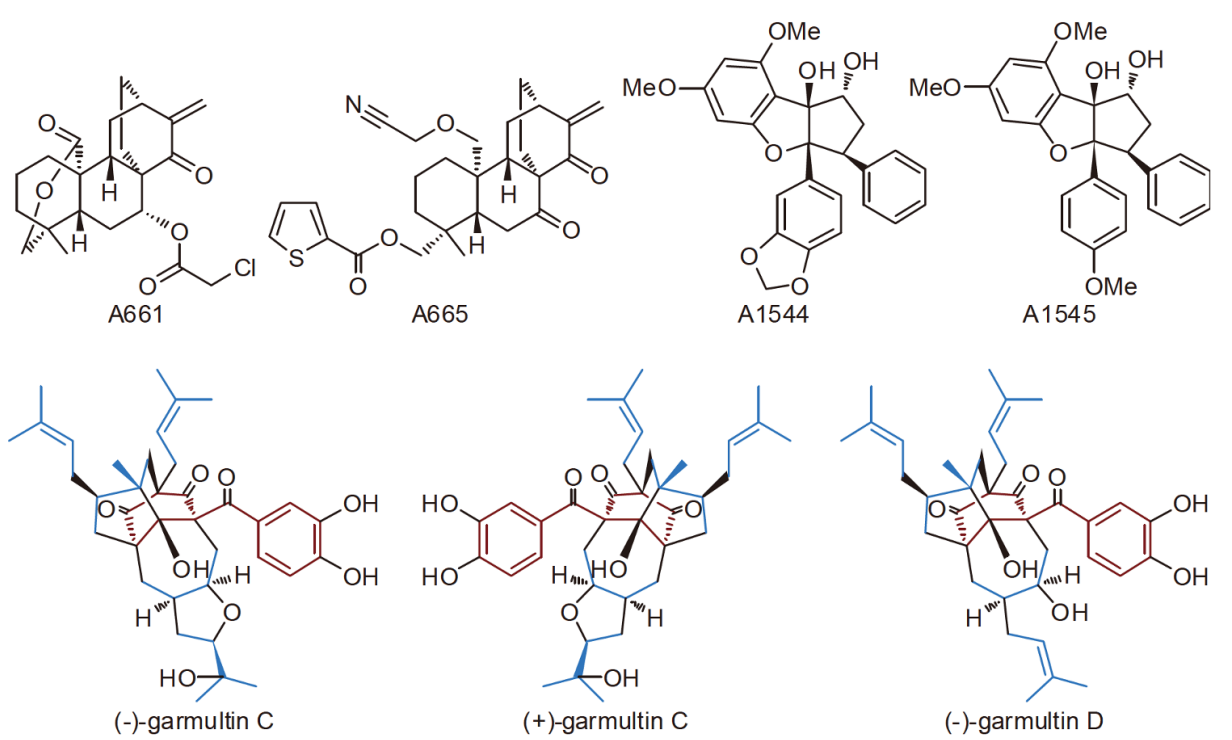

Figure 11 Structures of plant natural product modulators of the transcription factor Friend leukemia integration 1.

Fli-1 inhibitory activity in HEL cells. Indeed, it was the first time for PPAPs inhibiting Fli-1 protein (Tian et al., 2016).

\section{Speculations on natural product sciences}

In the early 20th century, few scientists specialized in natural products were found in the emerging departments of universities such as clinical biochemistry, pharmacology, toxicology, microbiology and cell biology. Natural product research remained appended to the department of chemistry as a research group. In the middle of the 20th century, some biologists and physiologists began to use natural products as experimental tools to influence and interfere with cellular functions. In the late 20th century, ecologists began to be interested in the roles of natural products in determining organism interactions. Nowadays, clearly, many disciplines, from chemistry to ecology, claim that natural products are part of their own discipline. Overall, the natural product research has changed dramatically over the past century. The evolution from a descriptive discipline to a holistic understanding of the functions and functional mechanisms of natural products in plants, microorganisms and other organisms has led to a wide and close intersection of natural product with other disciplines, such as plant physiology, pharmacy, cell biology, paleontology, ecology and biochemistry. These research results are widely used in many fields, such as agriculture, medicine, ecosystem management protection and basic sciences. Therefore, it can be predicted that the development trend of natural product research will be increasingly integrated into other disciplines. This tendency is a double-edged sword to the progress of natural product research because this field has been fragmented due to involvement in other disciplines, distracted by pursuing endowed functions, constrained at the level of isolation and structure elucidation.

During evolution, plants have acquired the ways in which a tremendous diversity of natural products are made (Chen et al., 2019). The presence of these compounds represents certain selective advantages due to their bioactivities that are vital for the functioning of the producer plants (plant physiology) (Liu et al., 2018), functions in determining species interactions (Wang and Niu, 2019; Yao et al., 2018) and in the complex interactions between plants and their abiotic environment (chemical ecology) (Shikano, 2017). Moreover, the values that natural products can be used for life-saving greatly influenced analytical and pharmaceutical chemistry (Harvey et al., 2015; Zhang et al., 2020), and chemistry of traditional Chinese medicines. The structure diversity of natural products directed major areas of organic chemistry, in particular, synthetic chemistry. These developments, together with integrating methodologies, technologies and conceptions from other disciplines, should constitute a platform for natural product sciences.

The roles played by plant natural products in producer plants are of the first importance. An inherent problem with these objects is the involvement of natural products in many crosslinking processes - it is difficult to know where to start disentangling this perplexity. One place to start may be at the level of metabolomes. For instance, SARs are important mechanisms of inhibiting pathogens and are inducible by exogenous substances including natural products. However, it has not been revealed whether SAR induces the production of defensive natural products to inhibit pathogens. RNA-seq analysis of mRNA levels and microRNA (miRNA) expression of the control and AHO-treated N. tabacum leaves in- 
dicated differentially expressed genes enriched in the pathways of phenylpropanoid biosynthesis, sesquiterpenoid and triterpenoid biosynthesis for protective cuticle and wax, respectively (Chen et al., 2017). This study urges the comparative metabolomic analyses of the control and AHOtreated $N$. tabacum leaves, which would unveil the functionalities of natural products not only in direct chemical defense but also in physical defense through producing protective wax and components of cuticle. Actually, one of the most successful steps in evolution has been the localized development of saturated, solid, and water insoluble waxes covering the surface of epidermal cells in plants. It is a system that confers some generalized immunity against many pathogens and at the same time functions against drought and cold.

The ways taken by natural products involved in adaptive evolution of plants are of importance as well. We hypothesize that SARs and/or innate immunity are the central driving forces for the adaptive evolution of plants on the basis of systemic acquired acclimation by manipulating the production of natural products, i.e., natural products are both the signals and the terminal performers of plant SARs and/or innate immunity. The mechanisms evolve through the natural selections acted on the inherent diverse functionalities and structural variations of plant natural products. One biosynthetic pathway produces more than one end products, and usually with several shunt products. Moreover, natural products are structurally flexible and thus can be readily modified by those pathway-outside enzymes. Natural selections in high throughput screen the activity of natural products. Accordingly, these bioactive natural products will improve the environmental adaptability of the producer plants on one side, and influence plant signaling to regulate natural product biosynthesis including selection of biosynthetic enzymes on the other side, forming a dynamic feedback loop centered at SARs and/or innate immunity. This hypothesis also can explain the mechanisms of systemic acquired acclimations.

Overall, the in-depth study on the effects of plant natural products on plant resistance to diseases, plant growth and development, environmental acclimations, plant evolution and biodiversity will make us deeply understand the biological significance of plant natural products.

Compliance and ethics The author(s) declare that they have no conflict of interest.

\section{References}

Cai, J.Y., Zhang, Y., Luo, S.H., Chen, D.Z., Tang, G.H., Yuan, C.M., Di, Y. T., Li, S.H., Hao, X.J., and He, H.P. (2012). Aphanamixoid A, a potent defensive limonoid, with a new carbon skeleton from Aphanamixis polystachya. Org Lett 14, 2524-2527.

Cao, M.M., Huang, S.D., Di, Y.T., Yuan, C.M., Zuo, G.Y., Gu, Y.C., Zhang, Y., and Hao, X.J. (2014a). Myrifabine, the first dimeric Myrioneuron alkaloid from Myrioneuron faberi. Org Lett 16, 528-531.
Cao, M.M., Zhang, Y., Li, X.H., Peng, Z.G., Jiang, J.D., Gu, Y.C., Di, Y.T., Li, X.N., Chen, D.Z., Xia, C.F., et al. (2014b). Cyclohexane-fused octahydroquinolizine alkaloids from Myrioneuron faberi with activity against hepatitis C virus. J Org Chem 79, 7945-7950.

Chattopadhyay, A.K., and Hanessian, S. (2017). Recent progress in the chemistry of Daphniphyllum alkaloids. Chem Rev 117, 4104-4146.

Chen, D.Z., Jing, C.X., Cai, J.Y., Wu, J.B., Wang, S., Yin, J.L., Li, X.N., Li, L., and Hao, X.J. (2016). Design, synthesis, and structural optimization of lycorine-derived phenanthridine derivatives as $\mathrm{Wnt} / \beta$-catenin signaling pathway agonists. J Nat Prod 79, 180-188.

Chen, Q., Jiang, T., Liu, Y.X., Liu, H., Zhao, T., Liu, Z., Gan, X., Hallab, A., Wang, X., He, J., et al. (2019). Recently duplicated sesterterpene (C25) gene clusters in Arabidopsis thaliana modulate root microbiota. Sci China Life Sci 62, 947-958.

Chen, Y. (1953). Benzoylisothiocyanate as a reagent for the identification of alcohols. Acta Chim Sin 19, 153-155.

Chen, Y., Dong, J., Bennetzen, J.L., Zhong, M., Yang, J., Zhang, J., Li, S., Hao, X., Zhang, Z., and Wang, X. (2017). Integrating transcriptome and microRNA analysis identifies genes and microRNAs for AHO-induced systemic acquired resistance in N. tabacum. Sci Rep 7, 12504.

Chi, Y.F., Kao, Y.S., and Chang, K.J. (1936). The alkaloids of Fritillaria roylei. I. Isolation of peimine ${ }^{1}$. J Am Chem Soc 58, 1306-1307.

Chou, T.Q. (1928). The alkaloids of Chinese Corydalis ambigua Cham. et Seh. (Yen-Hu-Suo). Part I. Chin J Physiol 2, 203-218.

Chu, J.H. (1955). An alkaloid of Chinese Aconitum, A. delavayi French. Acta Chim Sin 19, 332-335.

Chu, T.T., Hwang, W.K., and Loh, J.Y. (1955). A study of Fritillaria alkaloids III. Determination of the skeleton of peimine and peiminine by zinc dust distillation and selenium dehydrogenation. Acta Chim Sin 19, 232-240.

Chu, T.T., and Chou, T.Q. (1947). Conversion of peimine into peiminine and vice versa. J Am Chem Soc 69, 1257.

Di, Y.T., He, H.P., Liu, H.Y., Du, Z.Z., Tian, J.M., Yang, X.W., Wang, Y.H., and Hao, X.J. (2006a). Calycilactone A, a novel hexacyclic alkaloid from Daphniphyllum calycillum. Tetrahedron Lett 47, 5329-5331.

Di, Y.T., He, H.P., Lu, Y., Yi, P., Li, L., Wu, L., and Hao, X.J. (2006b). Alkaloids from the leaves of Daphniphyllum longeracemosum. J Nat Prod 69, 1074-1076.

Di, Y.T., Wee, C.S., Li, C.S., Kong, N.C., Wang, J.S., Fang, X., Zhu, H.J., Wu, Y.D., and Hao, X.J. (2014). Longphyllinesides A and B: natural Diels-Alder adducts from Daphniphyllum longeracemosum? Tetrahedron 70, 4017-4021.

Di, Y.T., He, H.P., Wang, Y.S., Li, L.B., Lu, Y., Gong, J.B., Fang, X., Kong, N.C., Li, S.L., Zhu, H.J., et al. (2007). Isolation, X-ray crystallography, and computational studies of calydaphninone, a new alkaloid from Daphniphyllum calycillum. Org Lett 9, 1355-1358.

Fang, S., Xiao-tian, L., Dequan, Y., Chang-fu, X., and Clardy, J. (1986). The structures of spirasine V and spirasine VI. Tetrahedron Lett 27, 275-278.

Fang, X., Di, Y., Geng, Z., Tan, C., Guo, J., Ning, J., and Hao, X. (2010). Trichiliton A, a novel limonoid from Trichilia connaroides. Eur J Org Chem 2010(7), 1381-1387.

Fang, X., Di, Y.T., and Hao, X.J. (2011). The advances in the limonoid chemistry of the Meliaceae family. Curr Org Chem 15, 1363-1391.

Fang, X., Di, Y.T., He, H.P., Liu, H.Y., Zhang, Z., Ren, Y.L., Gao, Z.L., Gao, S., and Hao, X.J. (2008). Cipadonoid A, a novel limonoid with an unprecedented skeleton, from Cipadessa cinerasecns. Org Lett 10, $1905-1908$.

Fang, X., Zhang, Q., Tan, C.J., Mu, S.Z., Lü, Y., Lu, Y.B., Zheng, Q.T., Di, Y.T., and Hao, X.J. (2009). Cipadonoids B-G, six new limonoids from Cipadessa cinerascens. Tetrahedron 65, 7408-7414.

Fu, Y., Zhang, Y., He, H., Hou, L., Di, Y., Li, S., Luo, X., and Hao, X. (2012). Strynuxlines A and B, alkaloids with an unprecedented carbon skeleton from Strychnos nux-vomica. J Nat Prod 75, 1987-1990.

Gao, S., Liu, H.Y., Wang, Y.H., He, H.P., Wang, J.S., Di, Y.T., Li, C.S., Fang, X., and Hao, X.J. (2007). Lathyranone A: a diterpenoid possessing an unprecedented skeleton from Euphorbia lathyris. Org 
Lett 9, 3453-3455.

Ge, Y., Liu, K., Zhang, J., Mu, S., and Hao, X. (2012a). The limonoids and their antitobacco mosaic virus (TMV) activities from Munronia unifoliolata Oliv.. J Agric Food Chem 60, 4289-4295.

Ge, Y.H., Zhang, J.X., Mu, S.Z., Chen, Y., Yang, F.M., Lü, Y., and Hao, X. J. (2012b). Munronoids A-J, ten new limonoids from Munronia unifoliolata Oliv. Tetrahedron 68, 566-572.

Goerig, M., and Schulte am Esch, J. (1991). Friedrich Wilhelm Adam Sertürner - dem Entdecker des Morphins zum 150. Todestag. Anästhesiol Intensivmed Notfallmed Schmerzther 26, 492-498.

Görlach, J., Volrath, S., Knauf-Beiter, G., Hengy, G., Beckhove, U., Kogel, K.H., Oostendorp, M., Staub, T., Ward, E., Kessmann, H., et al. (1996). Benzothiadiazole, a novel class of inducers of systemic acquired resistance, activates gene expression and disease resistance in wheat. Plant Cell 8, 629-643.

Gravel, E., and Poupon, E. (2010). Biosynthesis and biomimetic synthesis of alkaloids isolated from plants of the Nitraria and Myrioneuron genera: an unusual lysine-based metabolism. Nat Prod Rep 27, 32-56.

Artemisinin Structure Research Collaboration Group. (1977). A new sesquiterpene lactone-artemisinin. Chin Sci Bull 22, 142.

Guerra-Bubb, J., Croteau, R., and Williams, R.M. (2012). The early stages of taxol biosynthesis: an interim report on the synthesis and identification of early pathway metabolites. Nat Prod Rep 29, 683-696.

Guo, J., He, H.P., Fang, X., Di, Y.T., Li, S.L., Zhang, Z., Leng, Y., Hua, H. M., and Hao, X.J. (2010). Kansuinone, a novel euphane-type triterpene from Euphorbia kansui. Tetrahedron Lett 51, 6286-6289.

Guo, L.L., He, H.P., Di, Y.T., Li, S.F., Cheng, Y.Y., Yang, W., Li, Y., Yu, J. P., Zhang, Y., and Hao, X.J. (2012). Indole alkaloids from Ervatamia chinensis. Phytochemistry 74, 140-145.

Hao, X.J., ZHou, J., Manabu, N., and Kaoru, F. (1993). Calycinine A, a new alkaloid from the seed of Daphniphyllum calycinum. Acta Bot Yunnan 15, 205-207.

Hao, X. (2009). Chemical and biological study of Spiraea japonica Complex (in Chinese). Prog Chem 21, 84-99.

Hao, X., Shen, Y., Li, L., and He, H. (2003). The chemistry and biochemistry of Spiraea japonica complex. Curr Med Chem 10, 22532263.

Hao, X., Yang, C., Chen, S., and Zhou, J. (1985). The chemotaxonomy of Chinese species of the genus Aconitum L. (Ranunculaceae). Acta Phytotaxon Sin 23, 321-335.

Harvey, A.L., Edrada-Ebel, R.A., and Quinn, R.J. (2015). The reemergence of natural products for drug discovery in the genomics era. Nat Rev Drug Discov 14, 111-129.

He, X., Zhang, W., Yan, C., Nie, F., Li, C., Liu, X., Fei, C., Li, S., Song, X., Jia, Y., et al. (2017). Chemical biology reveals CARF as a positive regulator of canonical Wnt signaling by promoting $\mathrm{TCF} / \beta$-catenin transcriptional activity. Cell Discov 3, 17003.

Hu, X.J., Wang, Y.H., Kong, L.Y., He, H.P., Gao, S., Liu, H.Y., Ding, J., Xie, H., Di, Y.T., and Hao, X.J. (2009). New phenanthrenes from Trigonostemon lii Y.T. Chang. Tetrahedron Lett 50, 2917-2919.

Hu, Z.X., An, Q., Tang, H.Y., Yuan, C.M., Li, Y.N., Zhang, Y., and Hao, X. J. (2020). Stemtuberolines A-G, new alkaloids from Stemona tuberosa and their anti-TMV activity. Fitoterapia 143, 104572.

Hu, Z.X., Tang, H.Y., Guo, J., Aisa, H.A., Zhang, Y., and Hao, X.J. (2019). Alkaloids from the roots of Stemona tuberosa and their anti-tobacco mosaic virus activities. Tetrahedron 75, 1711-1716.

Huang, S.D., Zhang, Y., Cao, M.M., Di, Y.T., Tang, G.H., Peng, Z.G., Jiang, J.D., He, H.P., and Hao, X.J. (2013). Myriberine A, a new alkaloid with an unprecedented heteropentacyclic skeleton from Myrioneuron faberi. Org Lett 15, 590-593.

Kong, N.C., Zhang, Y., Gao, S., Lu, Y., Zheng, Q.T., Sun, Q.Y., Yang, F.M., Di, Y.T., and Hao, X.J. (2009). Structural elucidation of daphniacetal A, a new oxa-cage compound isolated from Daphniphyllum macropodum Miq.. Tetrahedron Lett 50, 957-959.

Kumar, M.S., Narla, A., Nonami, A., Mullally, A., Dimitrova, N., Ball, B., McAuley, J.R., Poveromo, L., Kutok, J.L., Galili, N., et al. (2011). Coordinate loss of a microRNA and protein-coding gene cooperate in the pathogenesis of 5q- syndrome. Blood 118, 4666-4673.

Li, C.S., Di, Y.T., Mu, S.Z., He, H.P., Zhang, Q., Fang, X., Zhang, Y., Li, S. L., Lu, Y., Gong, Y.Q., et al. (2008a). Daphniphyllum and diterpenoid alkaloids from Daphniphyllum longeracemosum. J Nat Prod 71, 12021206.

Li, C.S., Di, Y.T., He, H.P., Gao, S., Wang, Y.H., Lu, Y., Zhong, J.L., and Hao, X.J. (2007a). Daphlongeranines A and B, two novel alkaloids possessing unprecedented skeletons from Daphniphyllum longeracemosum. Org Lett 9, 2509-2512.

Li, L., He, H., Di, Y., Gao, S., and Hao, X. (2006). Daphnilongerine, an unprecedented fused pentacyclic ring system alkaloid from Daphniphyllum longeracemosum Rosenth.. Tetrahedron Lett 47, 6259-6262.

Li, M., Du, X.B., Shen, Y.M., Wang, B.G., and Hao, X.J. (1999). New diterpenoid alkaloids from Spiraea fritschiana var. parvifolia. Chin Chem Lett 10, 827-830.

Li, X.H., Zhang, Y., Zhang, J.H., Li, X.N., Cao, M.M., Di, Y.T., Peng, Z.G., Jiang, J.D., and Hao, X.J. (2016a). Myritonines A-C, alkaloids from Myrioneuron tonkinensis based on a novel hexacyclic skeleton. J Nat Prod 79, 1203-1207.

Li, Y., Hao, X., Li, S., He, H., Yan, X., Chen, Y., Dong, J., Zhang, Z., and Li, S. (2013). Eudesmanolides from Wedelia trilobata (L.) Hitchc. as potential inducers of plant systemic acquired resistance. J Agric Food Chem 61, 3884-3890.

Li, Y., Jia, Y., Zhang, Z., Chen, X., He, H., Fang, R., and Hao, X. (2007b). Purification and characterization of a new ribosome inactivating protein from cinchonaglycoside C-treated tobacco leaves. J Integrat Plant Biol 49, 1327-1333.

Li, Y., Wang, L., Li, S., Chen, X., Shen, Y., Zhang, Z., He, H., Xu, W., Shu, Y., Liang, G., et al. (2007c). Seco-pregnane steroids target the subgenomic RNA of alphavirus-like RNA viruses. Proc Natl Acad Sci USA 104, 8083-8088.

Li, Y., Xu, M., Ding, X., Yan, C., Song, Z., Chen, L., Huang, X., Wang, X., Jian, Y., Tang, G., et al. (2016b). Protein kinase C controls lysosome biogenesis independently of mTORC1. Nat Cell Biol 18, 1065-1077.

Li, Y., Zhang, Y., Gan, Q., Xu, M., Ding, X., Tang, G., Liang, J., Liu, K., Liu, X., Wang, X., et al. (2018). C. elegans-based screen identifies lysosome-damaging alkaloids that induce STAT3-dependent lysosomal cell death. Protein Cell 9, 1013-1026.

Li, Y., Zhang, Z., Jia, Y., Shen, Y., He, H., Fang, R., Chen, X., and Hao, X. (2008b). 3-Acetonyl-3-hydroxyoxindole: a new inducer of systemic acquired resistance in plants. Plant Biotech J 6, 301-308.

Liang, X.T. (1963). The structure of securinine. Sci China Ser A 12, 1525 1539.

Liu, C.P., Xu, J.B., Han, Y.S., Wainberg, M.A., and Yue, J.M. (2014). Trichiconins A-C, limonoids with new carbon skeletons from Trichilia connaroides. Org Lett 16, 5478-5481.

Liu, J., Mu, C., Yue, W., Li, J., Ma, B., Zhao, L., Liu, L., Chen, Q., Yan, C., Liu, H., et al. (2013). A diterpenoid derivate compound targets selenocysteine of thioredoxin reductases and induces Bax/Bakindependent apoptosis. Free Rad Biol Med 63, 485-494.

Liu, M., Wang, W.G., Sun, H.D., and Pu, J.X. (2017). Diterpenoids from Isodon species: an update. Nat Prod Rep 34, 1090-1140.

Liu, T., Xia, L., Yao, Y., Yan, C., Fan, Y., Gajendran, B., Yang, J., Li, Y.J., Chen, J., Filmus, J., et al. (2019). Identification of diterpenoid compounds that interfere with Fli-1 DNA binding to suppress leukemogenesis. Cell Death Dis 10, 117.

Liu, Z., Qanmber, G., Lu, L., Qin, W., Liu, J., Li, J., Ma, S., Yang, Z., and Yang, Z. (2018). Genome-wide analysis of BES1 genes in Gossypium revealed their evolutionary conserved roles in brassinosteroid signaling. Sci China Life Sci 61, 1566-1582.

Lu King, M., Chiang, C.C., Ling, H.C., Fujita, E., Ochiai, M., and McPhail, A.T. (1982). X-Ray crystal structure of rocaglamide, a novel antileulemic $1 H$-cyclopenta[ $b]$ benzofuran from Aglaia elliptifolia. J Chem Soc Chem Commun, 1150-1151.

Lv, C., Yan, X., Tu, Q., Di, Y., Yuan, C., Fang, X., Ben-David, Y., Xia, L., Gong, J., Shen, Y., et al. (2016). Isolation and asymmetric total 
synthesis of perforanoid A. Angew Chem Int Ed 55, 7539-7543.

Ma, Y., Mao, X.Y., Huang, L.J., Fan, Y.M., Gu, W., Yan, C., Huang, T., Zhang, J.X., Yuan, C.M., and Hao, X.J. (2016). Diterpene alkaloids and diterpenes from Spiraea japonica and their anti-tobacco mosaic virus activity. Fitoterapia 109, 8-13.

Oostendorp, M., Kunz, W., Dietrich, B., and Staub, T. (2001). Induced disease resistance in plants by chemicals. Eur J Plant Pathol 107, 19-28.

Osbourn, A., Goss, R.J.M., and Field, R.A. (2011). The saponins-polar isoprenoids with important and diverse biological activities. Nat Prod Rep 28, 1261-1268.

Qiao, Y.J., Shang, J.H., Wang, D., Zhu, H.T., Yang, C.R., and Zhang, Y.J. (2018). Research of Panax spp. in Kunming Institute of Botany, CAS. Nat Prod Bioprospect 8, 245-263.

Riggi, N., Suvà, M.L., De Vito, C., Provero, P., Stehle, J.C., Baumer, K., Cironi, L., Janiszewska, M., Petricevic, T., Suvà, D., et al. (2010). EWS-FLI-1 modulates miRNA145 and SOX2 expression to initiate mesenchymal stem cell reprogramming toward Ewing sarcoma cancer stem cells. Genes Dev 24, 916-932.

Sang, X., Chen, Y., Chen, W., Xie, J., Meng, G., Zhong, J., Li, T., and Lu, A. (2018). Celastrol specifically inhibits the activation of NLRP3 inflammasome. Sci China Life Sci 61, 355-357.

Savini, M., Zhao, Q., and Wang, M.C. (2019). Lysosomes: signaling hubs for metabolic sensing and longevity. Trends Cell Biol 29, 876-887.

Shikano, I. (2017). Evolutionary ecology of multitrophic interactions between plants, insect herbivores and entomopathogens. J Chem Ecol $43,586-598$.

Song, J., Yuan, C., Yang, J., Liu, T., Yao, Y., Xiao, X., Gajendran, B., Xu, D., Li, Y.J., Wang, C., et al. (2018). Novel flavagline-like compounds with potent Fli-1 inhibitory activity suppress diverse types of leukemia. FEBS J 285, 4631-4645.

Sun, H.D., Huang, S.X., and Han, Q.B. (2006). Diterpenoids from Isodon species and their biological activities. Nat Prod Rep 23, 673-698.

Tan, C., Di, Y., Wang, Y., Wang, Y., Mu, S., Gao, S., Zhang, Y., Kong, N., He, H., Zhang, J., et al. (2008). Oldhamine A, a novel alkaloid from Daphniphyllum oldhami. Tetrahedron Lett 49, 3376-3379.

Tan, C.J., Di, Y.T., Wang, Y.H., Zhang, Y., Si, Y.K., Zhang, Q., Gao, S., Hu, X.J., Fang, X., Li, S.F., et al. (2010). Three new indole alkaloids from Trigonostemon lii. Org Lett 12, 2370-2373.

Tan, Q.G., and Luo, X.D. (2011). Meliaceous limonoids: chemistry and biological activities. Chem Rev 111, 7437-7522.

Tang, G.H., He, H.P., Gu, Y.C., Di, Y.T., Wang, Y.H., Li, S.F., Li, S.L., Zhang, Y., and Hao, X.J. (2012). 3,4-seco-Diterpenoids from Trigonostemon flavidus. Tetrahedron 68, 9679-9684.

Tian, D.S., Yi, P., Xia, L., Xiao, X., Fan, Y.M., Gu, W., Huang, L.J., BenDavid, Y., Di, Y.T., Yuan, C.M., et al. (2016). Garmultins A-G, biogenetically related polycyclic acylphloroglucinols from Garcinia multiflora. Org Lett 18, 5904-5907.

Tong, L., Zhang, Y., He, H., and Hao, X. (2012). Four new limonoids from Aphanamixis grandifolia. Chin J Chem 30, 1261-1264.

Vergara, F., Rymen, B., Kuwahara, A., Sawada, Y., Sato, M., and Hirai, M. Y. (2017). Autopolyploidization, geographic origin, and metabolome evolution in Arabidopsis thaliana. Am J Bot 104, 905-914.

Wang, J., He, H., Shen, Y., and Hao, X. (2005). Sulfur-containing and dimeric flavanols from Glycosmis montana. Tetrahedron Lett 46, 169172

Wang, L., He, H.P., Di, Y.T., Zhang, Y., and Hao, X.J. (2012). Catharoseumine, a new monoterpenoid indole alkaloid possessing a peroxy bridge from Catharanthus roseus. Tetrahedron Lett 53, 15761578.

Wang, P., and Niu, B. (2019). Plant specialized metabolites modulate root microbiomes. Sci China Life Sci 62, 1111-1113.

Wang, S., Yin, J., Chen, D., Nie, F., Song, X., Fei, C., Miao, H., Jing, C., Ma, W., Wang, L., et al. (2013). Small-molecule modulation of Wnt signaling via modulating the Axin-LRP5/6 interaction. Nat Chem Biol 9, 579-585

Wang, W., Liu, H., Wang, S., Hao, X., and Li, L. (2011). A diterpenoid derivative 15 -oxospiramilactone inhibits $\mathrm{Wnt} / \beta$-catenin signaling and colon cancer cell tumorigenesis. Cell Res 21, 730-740.

Wang, X.N., Yin, S., Fan, C.Q., Wang, F.D., Lin, L.P., Ding, J., and Yue, J. M. (2006). Turrapubesins $A$ and $B$, first examples of halogenated and maleimide-bearing limonoids in nature from Turraea pubescens. Org Lett 8, 3845-3848.

Wang, Y.H., Zhang, Z.K., Yang, F.M., Sun, Q.Y., He, H.P., Di, Y.T., Mu, S. Z., Lu, Y., Chang, Y., Zheng, Q.T., et al. (2007a). Benzylphenethylamine alkaloids from Hosta plantaginea with inhibitory activity against tobacco mosaic virus and acetylcholinesterase. J Nat Prod 70, 1458-1461.

Wang, Y.H., Gao, S., Yang, F.M., Sun, Q.Y., Wang, J.S., Liu, H.Y., Li, C.S., Di, Y.T., Li, S.L., He, H.P., et al. (2007b). Structure elucidation and biomimetic synthesis of hostasinine A, a new benzylphenethylamine alkaloid from Hosta plantaginea. Org Lett 9, 5279-5281.

Ward, E.R., Uknes, S.J., Williams, S.C., Dincher, S.S., Wiederhold, D.L., Alexander, D.C., Ahl-Goy, P., Metraux, J.P., and Ryals, J.A. (1991). Coordinate gene activity in response to agents that induce systemic acquired resistance. Plant Cell 3, 1085-1094.

Wu, S.H., Luo, X.D., Ma, Y.B., Hao, X.J., Zhou, J., and Wu, D.G. (2001). Two new germacranolides from Magnolia grandiflora. J Asian Nat Prod Res 3, 95-102.

Xiang, G.X., Hu, H.Z., Chen, J.R., Chen, W.X., and Wu, L.S. (1995). A new agricultural antibiotic-ningnanmycin. Acta Microbiol Sin 36, 368374.

Yan, C., Huang, L., Liu, H.C., Chen, D.Z., Liu, H.Y., Li, X.H., Zhang, Y., Geng, M.Y., Chen, Q., and Hao, X.J. (2014). Spiramine derivatives induce apoptosis of $\mathrm{Bax}^{-/-} / \mathrm{Bak}^{-/-}$cell and cancer cells. Bioorg Med Chem Lett 24, 1884-1888.

Yan, X.H., Di, Y.T., Fang, X., Yang, S.Y., He, H.P., Li, S.L., Lu, Y., and Hao, X.J. (2011). Chemical constituents from fruits of Harrisonia perforata. Phytochemistry 72, 508-513.

Yan, X.H., Chen, J., Di, Y.T., Fang, X., Dong, J.H., Sang, P., Wang, Y.H., He, H.P., Zhang, Z.K., and Hao, X.J. (2010). Anti-tobacco mosaic virus (TMV) quassinoids from Brucea javanica (L.) Merr.. J Agric Food Chem 58, 1572-1577.

Yan, Y., Tang, L., Hu, J., Wang, J., Adelakun, T.A., Yang, D., Di, Y., Zhang, Y., and Hao, X. (2018). Munronin O, a potential activator for plant resistance. Pesticide Biochem Physiol 146, 13-18.

Yan, Y., Zhang, J.X., Huang, T., Mao, X.Y., Gu, W., He, H.P., Di, Y.T., Li, S.L., Chen, D.Z., Zhang, Y., et al. (2015). Bioactive limonoid constituents of Munronia henryi. J Nat Prod 78, 811-821.

Yang, W.Q., Shao, X.H., Deng, F., Hu, L.J., Xiong, Y., Huang, X.J., Fan, C. L., Jiang, R.W., Ye, W.C., and Wang, Y. (2020). Unprecedented quassinoids from Eurycoma longifolia: biogenetic evidence and antifeedant effects. J Nat Prod 83, 1674-1683.

Yang, X.W., Grossman, R.B., and Xu, G. (2018). Research progress of polycyclic polyprenylated acylphloroglucinols. Chem Rev 118, 35083558.

Yao, R., Li, J., and Xie, D. (2018). Recent advances in molecular basis for strigolactone action. Sci China Life Sci 61, 277-284.

Yue, W., Chen, Z., Liu, H., Yan, C., Chen, M., Feng, D., Yan, C., Wu, H., Du, L., Wang, Y., et al. (2014). A small natural molecule promotes mitochondrial fusion through inhibition of the deubiquitinase USP30. Cell Res 24, 482-496.

Zhang, Q., Di, Y.T., Li, C.S., Fang, X., Tan, C.J., Zhang, Z., Zhang, Y., He, H.P., Li, S.L., and Hao, X.J. (2009a). Daphenylline, a new alkaloid with an unusual skeleton, from Daphniphyllum longeracemosum. Org Lett $11,2357-2359$.

Zhang, T., Zhang, Y., Jiang, N., Zhao, X., Sang, X., Yang, N., Feng, Y., Chen, R., and Chen, Q. (2020). Dihydroartemisinin regulates the immune system by promotion of $\mathrm{CD} 8^{+} \mathrm{T}$ lymphocytes and suppression of B cell responses. Sci China Life Sci 63, 737-749.

Zhang, Y., Di, Y., He, H., Li, S., Lu, Y., Gong, N., and Hao, X. (2011). Daphmalenines A and B: two new alkaloids with unusual skeletons from Daphniphyllum himalense. Eur J Org Chem 2011(22), 4103-4107.

Zhang, Y., Di, Y.T., Zhang, Q., Mu, S.Z., Tan, C.J., Fang, X., He, H.P., Li, S.L., and Hao, X.J. (2009b). Daphhimalenine A, a new alkaloid with an 
unprecedented skeleton, from Daphniphyllum himalense. Org Lett 11, 5414-5417.

Zhang, Y., Ding, X., Shao, S., Guo, L.L., Zhao, Q., Hao, X.J., and He, H.P. (2019). Melocochines A and B, two alkaloids from the fruits of Melodinus cochinchinensis. Org Lett 21, 9272-9275.

Zhang, Z.Y., Sun, H., and Gu, Z.J. (2002). Karyomorphological study of the Spiraea japonica complex (Rosaceae). Brittonia 54, 168-174.

Zhang, Z., Fan, L., Yang, J., Hao, X., and Gu, Z. (2006). Alkaloid polymorphism and ITS sequence variation in the Spiraea japonica complex (Rosaceae) in China: traces of the biological effects of the Himalaya-Tibet Plateau uplift. Am J Bot 93, 762-769.

Zhao, L., He, F., Liu, H., Zhu, Y., Tian, W., Gao, P., He, H., Yue, W., Lei, X., Ni, B., et al. (2012). Natural diterpenoid compound elevates expression of Bim Protein, which interacts with antiapoptotic protein Bcl-2, converting it to proapoptotic Bax-like molecule. J Biol Chem 287, 1054-1065.

Zhao, N.D., Ding, X., Song, Y., Yang, D.Q., Yu, H.L., Adelakun, T.A.,
Qian, W.D., Zhang, Y., Di, Y.T., Gao, F., et al. (2018a). Identification of ingol and rhamnofolane diterpenoids from Euphorbia resinifera and their abilities to induce lysosomal biosynthesis. J Nat Prod 81, 1209 1218.

Zhao, Q., Gao, J.J., Qin, X.J., Hao, X.J., He, H.P., and Liu, H.Y. (2018b). Hedychins A and B, 6,7-dinorlabdane diterpenoids with a peroxide bridge from Hedychium forrestii. Org Lett 20, 704-707.

Zhou, J. (1964). Studies on the saponin components of plants in Yunnan I. Steroid saponins of Reineckea yunnanensis W. W. Smith. Acta Pharm Sin 11, 407-411.

Zhou, J., Huang, W., Wu, M., Yang, C., Feng, G., and Wu, Z. (1975). Triterpenoids from Panax Linn. and their relationship with taxonomy and geographical distribution. Acta Phytotaxon Sin 13, 29-48.

Zhu, X., Yuan, C., Tian, C., Li, C., Nie, F., Song, X., Zeng, R., Wu, D., Hao, X., and Li, L. (2018). The plant sesquiterpene lactone parthenolide inhibits Wnt/ $\beta$-catenin signaling by blocking synthesis of the transcriptional regulators TCF4/LEF1. J Biol Chem 293, 5335-5344. 